\title{
Vibration Control of a High-Speed Railway Bridge Using Multiple Tuned Mass Dampers
}

HEYDAR BEYGI 



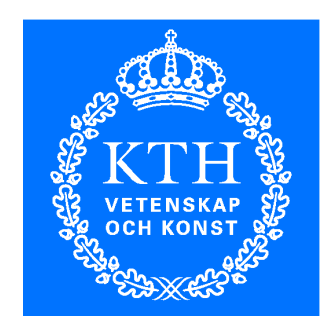

\section{Vibration Control of a High-Speed Railway Bridge Using Multiple Tuned Mass Dampers}

Heydar Beygi

November 2015

TRITA-BKN. Master Thesis 471, 2015

ISSN 1103-4297

ISRN KTH/BKN/EX-471-SE 
(C)Heydar Beygi 2015

Royal Institute of Technology, KTH

Department of Civil and Architectural Engineering Division of Structural Engineering and Bridges

Stockholm, Sweden, 2015 


\section{Acknowledgment}

I would like to give my sincere thanks to my supervisor and examiner Professor Raid Karoumi, head of the division of Structural Engineering and Bridges at KTH, Royal Institute of Technology, for his great support and supervision throughout this work. I would like to also thank Andreas Andersson, researcher at the division of Structural Engineering and Bridges at KTH, for his supports during this study.

My other thanks goes to my family specially my wife who has supported me during my studies, and my final thanks go to my fellow students, friends and teachers who made these years at KTH a great experience.

Stockholm, November 2015

Heydar Beygi 



\section{Abstract}

In the current thesis, the Banafjäl bridge located on the Bothnia line (Botniabanan) in northern Sweden was studied. The bridge is a $40 \mathrm{~m}$ long composite ballasted high-speed railway bridge. A 3D FE model of the bridge was developed using a commercial FE software, Abaqus. The FE model was calibrated against the measured data of the bridge. The dynamic response of the bridge's FE model was investigated under the dynamic load of the passing HSLM-A train using modal dynamic analysis. The vertical acceleration induced by excitation of the passing train exceeded the permissible limit of $3.5 \mathrm{~m} / \mathrm{s}^{2}$ for the speed range of $220-240 \mathrm{~km} / \mathrm{h}$. Thus, damping solutions using multiple tuned mass dampers (MTMDs) were investigated. According to the results of this study, a 4 tonnes MTMD system consist of 5 parallel TMDs attached to the mid-span of the bridge could effectively control the undesired vibration of the bridge. The suggested solution could account for the changes in the stiffness of the bridge caused by freezing and ice forming in the ballast.

Keywords: Tuned mass dampers, Dynamic analysis, high-speed railway bridge, Banafjäl bridge 



\section{Contents}

Acknowledgment $\quad$ v

Abstract vii

1 Introduction $\quad 1$

1.1 Structural control systems . . . . . . . . . . . . . . . 1

1.1.1 Passive control systems . . . . . . . . . . . . . . . 2

1.2 Tuned Mass Damper (TMD) . . . . . . . . . . . . . . 2

1.3 Modal dynamic analysis . . . . . . . . . . . . . . . . . . 6

1.3.1 Structural damping . . . . . . . . . . . . . . 7

1.4 The Banafjäl Bridge . . . . . . . . . . . . . . . . . . . 8

1.5 Aim and scope ....................... 9

2 The modeling approach $\quad 11$

$2.13 \mathrm{D}$ finite element $\operatorname{model}(\mathrm{FEM}) \ldots \ldots . \ldots . . \ldots 11$

2.1.1 The steel girders . . . . . . . . . . . . . . 11

2.1.2 The concrete slab . . . . . . . . . . . . . . . 11

2.1.3 The ballast . . . . . . . . . . . . . . 12

2.1.4 The rail track . . . . . . . . . . . . . . . 13

2.1.5 Materials .................... 14

2.1.6 Damping. . . . . . . . . . . . . . . . . . 14

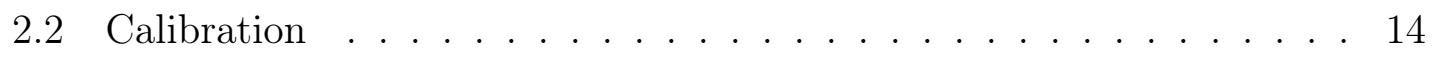

2.3 Dynamic analysis . . . . . . . . . . . . . . . . 16

2.3.1 Dynamic load . . . . . . . . . . . . . 16 
2.4 Verification of the model . . . . . . . . . . . . . . . . . . 17

2.5 Convergence analysis . . . . . . . . . . . . . . . . . . . 18

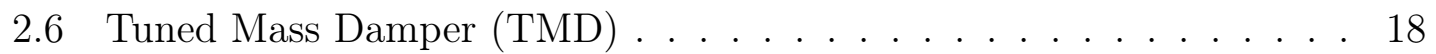

2.7 Sensitivity analysis . . . . . . . . . . . . . . . . . . . . . . . 21

3 Analysis and results $\quad 23$

3.1 Dynamic characteristics of the FE model . . . . . . . . . . . . . 23

3.2 Application of TMDs . . . . . . . . . . . . . . . . . . . 24

3.3 Sensitivity analysis . . . . . . . . . . . . . . . . . 30

4 Conclusions and future studies 33

4.1 Conclusions . . . . . . . . . . . . . . . . . . . . 33

4.2 MTMD design procedure . . . . . . . . . . . . . . 34

4.3 Future studies . . . . . . . . . . . . . . . . . . . 35

$\begin{array}{ll}\text { Bibliography } & 37\end{array}$

$\begin{array}{ll}\text { A Python code } & \text { A1 }\end{array}$

$\begin{array}{ll}\text { B Extended summary } & \text { B1 }\end{array}$

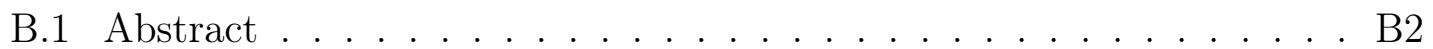

B.2 Introduction . . . . . . . . . . . . . . . B 2

B.3 Modeling and analysis . . . . . . . . . . . . . . B5

B.3.1 The Banafjäl Bridge . . . . . . . . . . . . . . B5

B.3.2 Numerical evaluation of the TMDs . . . . . . . . . . . B5

B.3.3 Application of TMDs . . . . . . . . . . . . B8

B.3.4 Sensitivity analysis . . . . . . . . . . . . . . . B14

B.4 Conclusions . . . . . . . . . . . . . . . . . . B17

B.5 Design procedure of MTMD systems . . . . . . . . . . . . . B17

B.6 Future studies . . . . . . . . . . . . . . . . . . . . . . . B18 


\section{Chapter 1}

\section{Introduction}

High speed railway systems have become an important part of the national economy in developed countries. Therefore there is a growing demand to increase the permissible axle load and the speed in the existing railways. Dynamic response of the bridge is one of the limiting components in bridges especially in the High speed railway tracks (Xia and Zhang, 2005).

In this study, the dynamic response of an existing high-speed railway bridge, is going to be investigated. In the case of unsatisfying response of the bridge, effectiveness of an external damping system will be investigated and a suitable damping solution will be proposed.

\subsection{Structural control systems}

Structural control systems or motion control systems are additional systems added to the main structure that can reduce the response of the main structure subjected to a dynamic load e.g. seismic load, wind load and traffic load. Based on their control strategies, structural control systems are classifies into three main categories: active, semi-active and passive control systems. In some litterateurs hybrid control systems are also introduced as an additional category which is in fact is a combination of an active or semi-active control system with a passive control system. The main difference between active and passive control systems is that the passive control systems utilize the motion of the primary structure to perform, while the active control systems need an external power supply to apply on the primary structure in order to counteract the motion of the structure. On the other hand, semi-active control systems use less energy than the active control systems. Passive control systems have a higher degree of reliability and they are more cost effective but with limited capacity while active control systems are more adoptable and have a higher range of capacity. Semi active control systems fit somewhere in between. (Amezquita-Sanchez et al. (2014), Saaed et al. (2015), Michalakis C Constantinou (1998) and Mai (2014)). 


\subsubsection{Passive control systems}

Passive control systems utilize the energy produced by the motion of the primary structure and thereby dissipate a portion of the input energy from the dynamic load. Since theses control systems produce higher damping force when the dynamic response of the main structure is higher, they have been considered as smart control systems in the past.

Passive control systems have two main categories: seismic isolation and energy dissipation devices. Seismic isolation systems as it clear from the name, are mainly used in order to protection civil structures which is out of the scope of this study.

Energy dissipation devices are small elements relative to the main structure, attached to the structure to absorb or divert part of the input energy. These systems classified based on there basic principles as following: Hysteretic devices that utilize either the plastic deformation of metals or friction to dissipate the input energy; Viscoelastic (VE) devices that utilize the in relative speed between two ends of the control system and the viscosity of the device to convert the input energy to heat; and Dynamic vibration absorbers that transfer a part of the input energy from the main structure to the attached absorber and have three main types: tuned mass dampers (TMDs) tuned liquid dampers(TLDs) and tuned liquid column dampers(TLCDs). (Saaed et al. (2015), Michalakis C Constantinou (1998))

In the current study the application of passive TMDs to mitigate the vibration of a high-speed railway bridge is to be investigated.

\subsection{Tuned Mass Damper (TMD)}

Tuned Mass Damper (TMD) is among the oldest types of vibration absorbers. It is invented by Frahm in 1909 (Den Hartog (1956) and Chopra (2012)).

A simple undamped structure with attached TMD behave like a simple two degree of freedom system without damping(see figure 1.1).

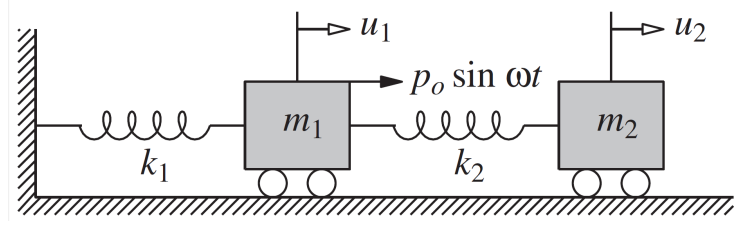

Figure 1.1: A two DOF system(Chopra, 2012)

The equation of motion of such a system (figure 1.1) exited by a harmonic force of $P(t)=P_{o} \cdot \sin (\omega t)$ which act on the first mass (i.e. the main structure), can be written as: 


$$
\left[\begin{array}{cc}
m_{1} & 0 \\
0 & m_{2}
\end{array}\right]\left[\begin{array}{c}
\ddot{u_{1}} \\
\ddot{u_{2}}
\end{array}\right]+\left[\begin{array}{cc}
k_{1}+k_{2} & -k_{2} \\
-k_{2} & -k_{2}
\end{array}\right]\left[\begin{array}{l}
u_{1} \\
u_{2}
\end{array}\right]=\left[\begin{array}{c}
p_{o} \\
0
\end{array}\right] \sin (\omega t)
$$

The forced vibration of this system in the steady state condition can be assumed as:

$$
\left[\begin{array}{l}
u_{1}(t) \\
u_{2}(t)
\end{array}\right]=\left[\begin{array}{l}
u_{1 o} \\
u_{2 o}
\end{array}\right] \sin (\omega t)
$$

Substituting equation 1.2 in equation 1.1, the result would be an algebraic equation as:

$$
\left[\begin{array}{cc}
k_{1}+k_{2}-m_{1} \omega^{2} & -k_{2} \\
-k_{2} & k_{2}-m_{2} \omega^{2}
\end{array}\right]\left[\begin{array}{l}
u_{1 o} \\
u_{2 o}
\end{array}\right]=\left[\begin{array}{c}
p_{o} \\
0
\end{array}\right]
$$

or

$$
\left[\mathbf{k}-\omega^{2} \mathbf{m}\right]\left[\begin{array}{l}
u_{1 o} \\
u_{2 o}
\end{array}\right]=\left[\begin{array}{c}
p_{o} \\
0
\end{array}\right]
$$

that can be solved for $u_{1 o}$ and $u_{2 o}$ as:

$$
\left[\begin{array}{l}
u_{1 o} \\
u_{2 o}
\end{array}\right]=\left[\mathbf{k}-\omega^{2} \mathbf{m}\right]^{-1}\left[\begin{array}{c}
p_{o} \\
0
\end{array}\right]
$$

that gives:

$$
\left\{\begin{array}{l}
u_{1 o}=\frac{p_{o}\left(k_{2}-m_{2} \omega^{2}\right)}{m_{1} m_{2}\left(\omega^{2}-\omega_{1}^{2}\right)\left(\omega^{2}-\omega_{2}^{2}\right)} \\
u_{2 o}=\frac{p_{o} k_{2}}{m_{1} m_{2}\left(\omega^{2}-\omega_{1}^{2}\right)\left(\omega^{2}-\omega_{2}^{2}\right)}
\end{array}\right.
$$

By defining the following dimensionless symbols:

$$
\omega_{1}=\sqrt{\frac{k_{1}}{m_{1}}} \quad \text { and } \quad \omega_{2}=\sqrt{\frac{k_{2}}{m_{2}}} \quad \text { and } \quad \mu=\frac{m_{2}}{m_{1}}
$$

in which, $\omega_{1}, \omega_{2}$ and $\mu$ are: the natural frequency of the first mass, the natural frequency of the second mass and the mass ratio of the two masses respectively. By substituting these symbols in the equation 1.6 we can obtain: 


$$
\left\{\begin{array}{l}
u_{1 o}=\frac{p_{o}}{k_{1}} \frac{1-\left(\omega / \omega_{2}\right)^{2}}{\left[1+\mu\left(\omega_{2} / \omega_{1}\right)^{2}-\left(\omega / \omega_{1}\right)^{2}\right]\left[1-\mu\left(\omega / \omega_{2}\right)^{2}\right]-\mu\left(\omega_{2} / \omega_{1}\right)^{2}} \\
u_{2 o}=\frac{p_{o}}{k_{1}} \frac{1}{\left[1+\mu\left(\omega_{2} / \omega_{1}\right)^{2}-\left(\omega / \omega_{1}\right)^{2}\right]\left[1-\mu\left(\omega / \omega_{2}\right)^{2}\right]-\mu\left(\omega_{2} / \omega_{1}\right)^{2}}
\end{array}\right.
$$

According to the first part of this equation, $u_{1 o}$ is zero when $1-\left(\omega / \omega_{2}\right)^{2}$ is zero. In other words, when the natural frequency of the second mass (i.e. the vibration absorber) is equal to the frequency of the force, the vibration of the first mass (i.e. the main structure) is zero. Thus by tuning the vibration absorber o the frequency of the external force, vibration of the main structure can be prevented. Figure 1.2 shows the response amplitude of the first mass $\left(m_{1}\right)$, when $\omega_{1}=\omega_{2}$ (i.e. the second mass tuned to the natural frequency of the main mass), and the mass ratio is $\mu=0.2$ and $u_{1 s t o}=p_{o} / k_{1}$.

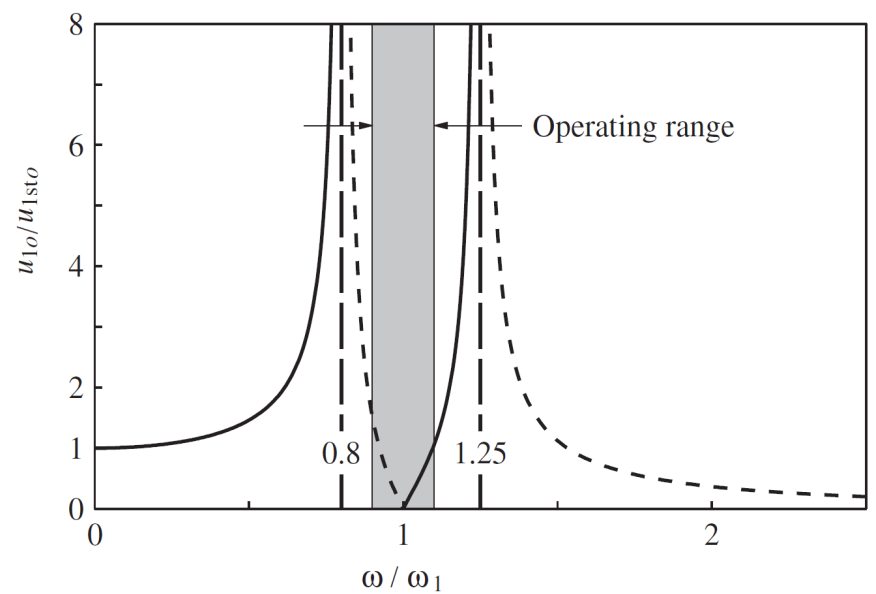

Figure 1.2: Response amplitude of the first mass versus the exiting frequency when $\omega_{1}=\omega_{2}$ and $\mu=0.2$ (Chopra, 2012)

Furthermore, when $\omega=\omega_{2}$, the second part of the equation 1.8 will reduce to:

$$
u_{2 o}=-\frac{p_{o}}{k_{2}}
$$

that means, while the motion of the first mass is zero, the vibration of the second mass is $-p_{0} / k_{2} \cdot \sin (\omega t)$ which produce the force of $-p_{0} \cdot \sin (\omega t)$ in second mass spring that is in fact equal and opposite to the external force.

This behavior is the main concept behind the using of the TMDs, in which by attaching a tuned relatively small mass to the main structure, the undesired vibration due to an external force can be prevented.

Equation 1.9 also imply that since the force acting on the absorber is:

$$
k_{2} u_{2 o}=\omega^{2} m_{2} u_{2 o}=-p_{o}
$$


The mass and stiffness of the TMD depend on the permissible motion of the TMD, since the smaller mass lead to larger amplitude of the TMD. Moreover, while the larger mass of the TMD is difficult to handle, the smaller mass decrease the operating range of the TMD.

TMD can be highly effective in suppressing the resonance response due to the external force, when it is tuned to the resonance frequency.

Den Hartog (1956) suggested a method to determine the optimal parameters of a damped TMD that attached to an undamped SDOF system, to minimize the steady state response of the main mass subjected to a harmonic load as following:

$$
\begin{gathered}
f=\frac{1}{1+\mu} \\
\zeta=\sqrt{\frac{3 \mu}{8(1+\mu)^{3}}}
\end{gathered}
$$

where $f$, and $\zeta$ are frequency ratio and damping ratio of the TMD, defined as:

$$
f=\frac{\omega_{2}}{\omega_{1}} \quad \text { and } \quad \zeta=\frac{c}{2 \sqrt{k_{2} m_{2}}}
$$

where, $\omega_{2}, k_{2}, m_{2}$ and $c$, are the natural frequency, stiffness, mass and the damping of the TMD respectively and $\omega_{1}$ is the natural frequency of the main structure. In the structures with damping, however, the optimal TMD parameters should be obtained by using numerical methods(Rana and Soong, 1998)

TMDs have been applied in tall buildings to mitigate the vibration induced by wind and moderate earthquakes (Rana and Soong, 1998). Gutierrez Soto and Adeli (2013) present several real cases of application of TMDs in existing high rise buildings and towers around the world.

Application and effectiveness of the TMDs in suppressing wind induced vibration in long span bridges have been investigated and approved (Lin et al. (2000), Gu et al. (1998), Honda et al. (1993), Domaneschi et al. (2015))

Hoang et al. (2008) investigated the seismic application of the TMDs and suggested the optimal design parameters of the TMDs. Kwon et al. (1998) investigated the application of TMDs in vibration control of bridges under the moving loads that lead to decrease in the vibration and quick dy out of the free vibration. Performance of the TMDs in vibration reduction of the railway bridges under the excitation of the high-speed trains have also been studied (Yau and Yang (2004b), Wang et al. (2003))

One of the main limiting characteristics of the STMDs is the narrow performance frequency range. One way to increase the performance range, is to use multiple tuned mass dampers(MTMDs). Multiple tuned mass dampers can be designed in either parallel or series configurations.(Kareem and Kline, 1995) Previous studies have 
shown that multiple tuned mass dampers (MTMDs) are more effective and more robust than single tuned mass dampers (STMDs) (Yamaguchi and Harnpornchai (1993), Igusa and Xu (1994))

Previous studies have shown the effectiveness of the MTMDs in suppressing the railway bridge vibrations induced by high speed trains. Lin and Chen (2005) studied the effect of the MTMDs using a simplified simply supported 2D beam as a bridge model excited by a passing high-speed train. They concluded that a $2 \%$ MTMD mass ratio, can reduce the maximum vertical acceleration by $57 \%$. Li et al. (2005) also investigated a simply supported girder model under the passing high-speed train and examined the response of the model in presence of MTMDs. They concluded that the maximum vertical dynamic deflection can be reduced by up to $61 \%$ for a $30 \mathrm{~m}$ long girder.

\subsection{Modal dynamic analysis}

The equations of motion of a damped MDOF system are(Chopra, 2012):

$$
\mathbf{m} \ddot{\mathbf{u}}+\mathbf{c} \dot{\mathbf{u}}+\mathbf{k u}=\mathbf{p}(t)
$$

The displacement vector $\mathbf{u}$ of an MDOF system can be described using modal contributions, by which, the dynamic response of the system can be written as:

$$
\mathbf{u}(t)=\sum_{r=1}^{N} \phi_{r} q_{r}(t)=\Phi \mathbf{q}(t)
$$

where $\phi_{n}$ is the natural modes of the vibration of the undamped system and $q_{n}(t)$ is a simple harmonic function:

$$
q_{n}(t)=A_{n} \cos \left(\omega_{n} t\right)+B_{n} \sin \left(\omega_{n} t\right)
$$

By substituting the equation 1.15 into the equation 1.14 and multiply each side by $\phi_{n}^{T}$ we can obtain:

is a simple harmonic function:

$$
\sum_{n=1}^{N} \phi_{n}^{T} \mathbf{m} \phi_{r} \ddot{q}_{r}(t)+\sum_{n=1}^{N} \phi_{n}^{T} \mathbf{c} \phi_{r} \dot{q}_{r}(t)+\sum_{n=1}^{N} \phi_{n}^{T} \mathbf{k} \phi_{r} q_{r}(t)=\phi_{n}^{T} \mathbf{p}(t)
$$

By assuming the classical damping for the system, in which the damping matrix $\mathrm{C}$ is diagonal, because of the orthogonality of the modes, equation 1.17 can be rewritten as:

$$
M_{n} \ddot{q}_{r}(t)+C_{n} \dot{q}_{r}(t)+K_{n} q_{r}(t)=P_{n}(t)
$$


where :

$$
M_{n}=\phi_{n}^{T} \mathbf{m} \phi_{r} \quad C_{n}=\phi_{n}^{T} \mathbf{c} \phi_{r} \quad K_{n}=\phi_{n}^{T} \mathbf{k} \phi_{r} \quad P_{n}(t)=\phi_{n}^{T} \mathbf{p}(t)
$$

where $M_{n}, C_{n}, K_{n}, P_{n}(t)$, are generalized mass, generalized damping, generalized stiffness and generalized force for the $n$th mode $\phi_{n}$ respectively. These parameters only depend on the $n$th mode $\phi_{n}$. In other words, equation 1.18 represent an SDOF system with the natural frequency of $\phi_{n}$. Therefore, by knowing each mode, equation 1.18 can be solved for $q_{n}$, independent form other modes of the system. Thus, there is $\mathrm{n}(\mathrm{n}=1,2,3, \ldots, \mathrm{N})$ uncoupled equation bast on equation 1.18 which can be rewritten as:

$$
\mathbf{M} \ddot{\mathbf{q}}+\mathbf{C} \dot{\mathbf{q}}+\mathbf{K q}=\mathbf{P}(t)
$$

\subsubsection{Structural damping}

The process that constantly decrease the amplitude of the vibration of the structures is called damping. Damping is the results of different mechanisms that may occur simultaneously in the structures such as: thermal effect of elastic strain; internal friction; friction in the connections; opening and closing of micro-cracks etc. Since identifying and modeling all of the mentioned mechanisms of damping is difficult, thus the energy-dissipating property of the structures usually idealized as an equivalent viscous damping. This means that the damping coefficient of an imaginary linear viscose damper or dashpot selected in a way that its damping is equivalent to the energy dissipation of the combination of all of the real damping mechanisms that occurs in the real structure. Therefore the damping force in the equation of the motion of the structure can be determined as (Chopra, 2012):

$$
f_{D}=c \dot{u}
$$

where the constant $\mathrm{c}$ is the viscose damping coefficient, and $\dot{u}$ is the speed of the motion of the structure.

The damping ratio i.e. the ratio of the damping to the critical damping of the structure can be defined as:

$$
\zeta=\frac{c}{2 \sqrt{k m}}
$$

where $k$ and $m$ are the stiffness and mass of the structure respectively. 


\subsection{The Banafjäl Bridge}

The Banafjäl Bridge, located on the Botniabanan, is a $42 \mathrm{~m}$ long simply supported high-speed railway bridge (figure 1.3).

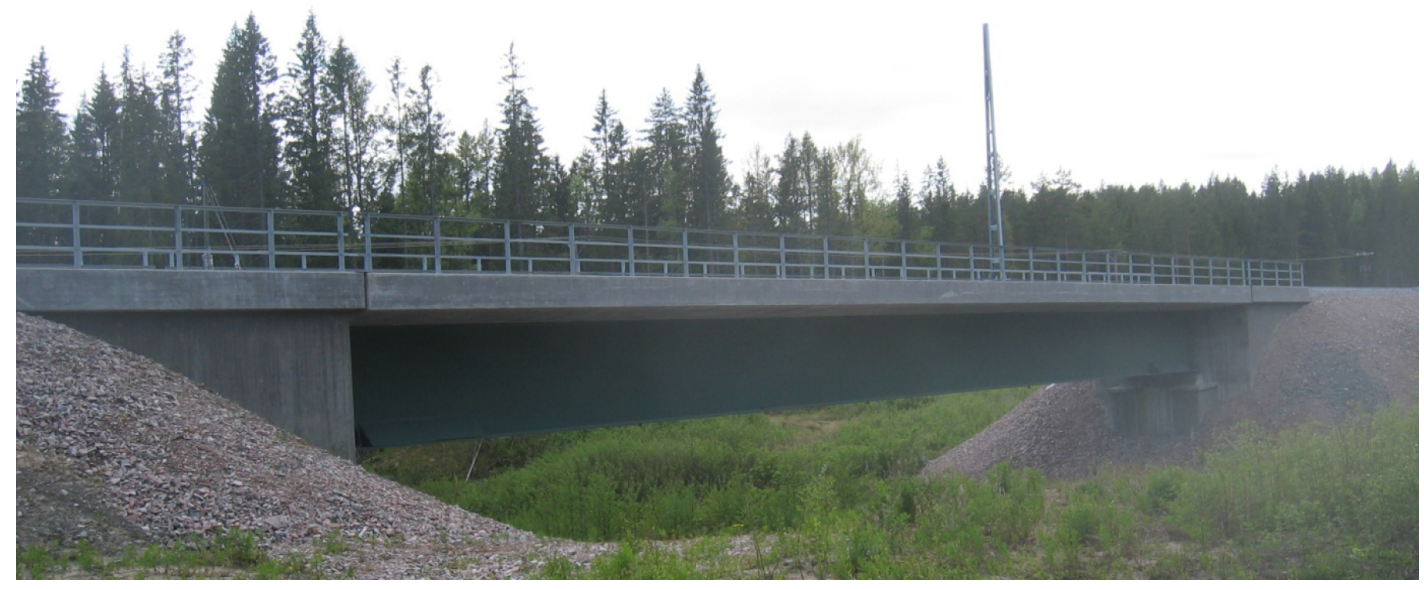

Figure 1.3: The Banafjäl Bridge(Gillet, 2010)

The bridge's deck is consisted of a concrete slab that is carried by two steel girders i.e. I beams. The bridge has a horizontal curvature with the radius of $4000 \mathrm{~m}$. The concrete slab is $7.7 \mathrm{~m}$ wide and its thickness is varying from $250 \mathrm{~mm}$ to $400 \mathrm{~mm}$ (see figure 1.4).

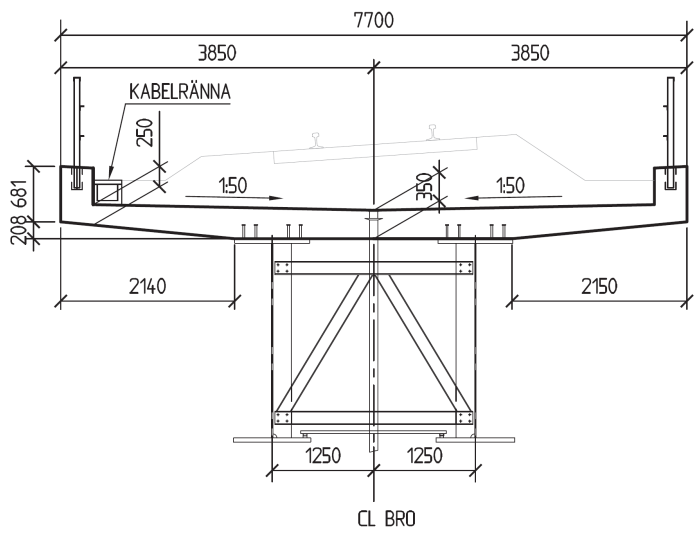

Figure 1.4: The cross section of the Banafjäl Bridge(Scandiaconsult, 2002)

Each girder is made of three I beams in the longitudinal direction i.e. two sidebeams and one mid-beam. The two side-beams have an identical cross section but different from the mid-beam. The girder's height is $2.5 \mathrm{~m}$. The two girders are connected to each other by means of cross beams in seven position along the bridge. The connectors in the location of the supports of the bridge are S-shape and the rest of the connectors in between are triangle-shaped(Figure 1.5). 

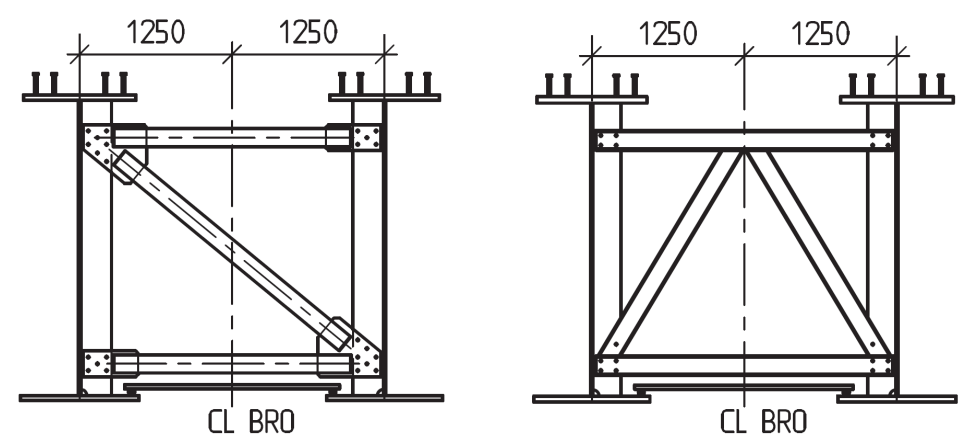

Figure 1.5: Two different arrangement of girder connectors, S-shape (left) and triangle-shaped (right).

The slab's concrete quality is K40 (C32/40) and steel quality are S460M in the flanges and S420M in the web of the girders respectively.

\subsection{Aim and scope}

As mentioned before, in most of the previous studies, the study bridges, are highly simplified and mostly modeled as a single 2D simply supported beams. This could lead to some limitations in applying their results to design a MTMD system for real cases. Therefor, the main aim of this study is to develop a more realistic 3D finite element (FE) model of an existing bridge and whereby, investigate the applicability of the MTMD systems. Furthermore, by examining different parameters of the MTMDs, a design recipe for real case application of MTMDs will be presented.

In this study, the available data of Banafjäl Bridge that is a high-speed composite railway bridge was utilized.

In spite of all of the efforts, this study has also some limitations caused by assumptions and simplifications. First, all of the numerical simulations have some errors relative to the exact solutions. Besides that, there are some other limitation in this work which are the results of the simplifications and assumptions. The main limitations of this work are listed below:

- In this study the horizontal curvature of the bridge and the transverse slope of the ballast were neglected that can results in neglecting torsional modes.

- The model was assumed perfectly linear and any non-linearity in the bridge was neglected.

- All parts of the model were assumed to be rigidly connected without any slips. Thus the damping and elastic behavior of the connectors between rails and sleepers were neglected.

- Any dynamic effects of the foundation and supports were neglected. 
- The dynamic load of the passing trains were modeled as moving point load and whereby, any damping and elastic behavior of the suspension system of the vehicle were also neglected. 


\section{Chapter 2}

\section{The modeling approach}

\subsection{D finite element model(FEM)}

A linear elastic 3D FEM of the Banafjäl bridge was developed using the commercial FEM software, ABAQUS. For simplification, the horizontal curvature and the transverse slope of the rail-ballast system of the bridge was neglected. Thus the bridge was modeled as perfectly straight without any slop or inclination in both longitudinal and transverse direction.

The developed 3D FEM was consist of different parts including: two steel girders; the steel cross beams that connected the two girders together; the concrete slab; the ballast; the rails and the concrete sleepers. All parts of the bridge were assumed to be rigidly connected to each other without any slip whatsoever.

\subsubsection{The steel girders}

Each steel girder was designed as detailed as possible including all of its stiffeners and its longitudinal changes. The two girders were connected together using the cross beams. The design values of the material coefficients of steel were extracted from Eurocode 3 (EN-1993-1-1, 2005). The design coefficient utilized in this study is given in table (2.2). Three-dimensional shell elements with reduced integration (S8R) were used to model the girders.

\subsubsection{The concrete slab}

The concrete slab of the bridge were modeled according to the design drawings of the bridge (figure 1.4). The stiffness of the concrete was assumed to be $37 \mathrm{GPa}$. That is slightly higher than the design value of the concrete $(\mathrm{C} 32 / 40)$, in order to reproduce the correct dynamic response. This value is not far from the values measured by Gonzales et al. (2013) for The Skidträsk bridge which have the properties close to the Banafjäl bridge. Three-dimensional second order solid elements with reduced 
integration(C3D20R) were used to model the concrete slab.

\subsubsection{The ballast}

The ballast of the Banafjäl bridge has a transverse inclination, but in this study the ballast was assumed to be horizontal. The depth of the ballast at the center line of the bridge was assumed to be $0.6 \mathrm{~m}$ and its material properties was extracted from The standard code provided by Swedish Rail Administration (Banverket). Thus the ballast specific weight was assumed to be $20 \mathrm{kN} / \mathrm{m}^{3}$ (Banverket-a, 2008).

According to measurement carried out by Gonzales et al. (2013) on the Skidträsk bridge located in the northern Sweden, the stiffness of the bridge alter significantly due to the change in the stiffness of the ballast as a result of seasonal change in temperature. In other words, during the cold season due to the freezing and ice forming, the ballast become stiffer and alter the dynamic characteristics of the bridge (see figure 2.1).

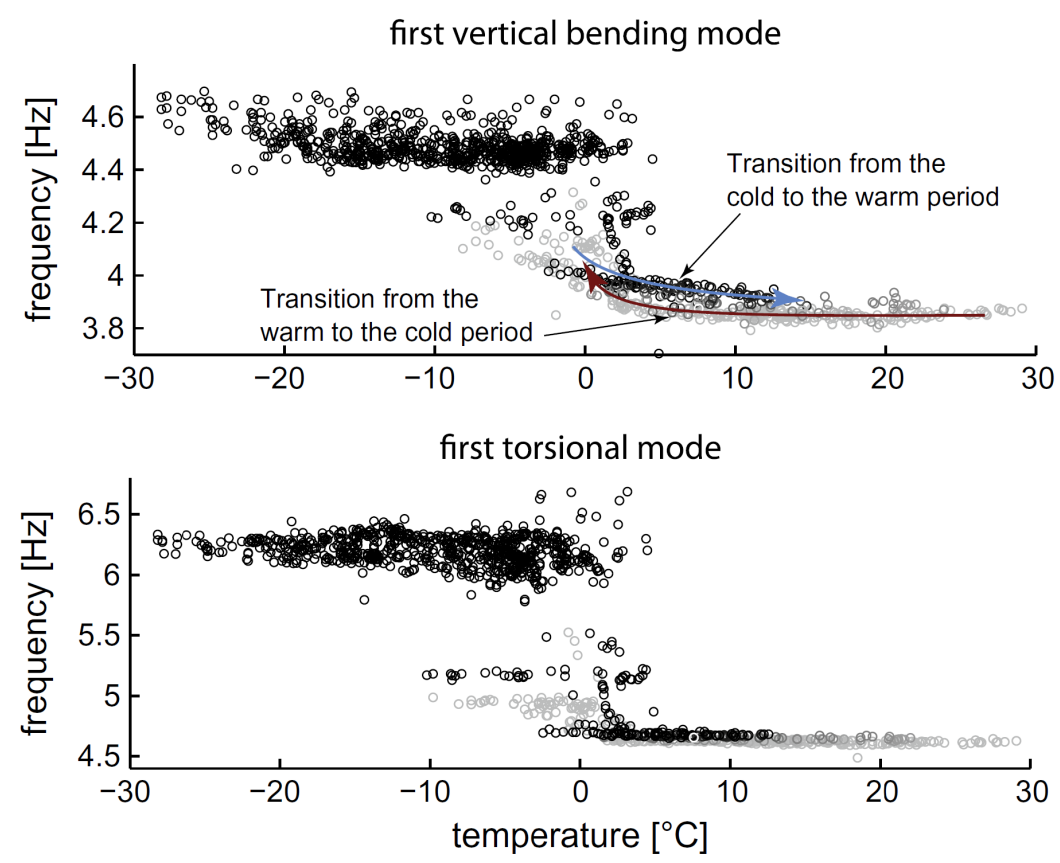

Figure 2.1: The effect of temperature on the frequency of the first vertical bending mode (top) and the first torsional mode (bottom) (after Gonzales et al. (2013))

As indicated in the figure (2.1), there is a clear shift in the dynamic properties of the Skidträsk bridge when the temperature become sub-zero. According to Gonzales et al. (2013), the stiffness of the ballast varies from $200 M P a$ in the warm season to $1400 \mathrm{MPa}$ in the cold season. Thus in the current study the properties of the ballast in the warm season (i.e. $E_{\text {ballast }}=200 M P a$ ) were used in main modeling process, but the effect of cold temperature was assessed in the sensitivity analysis. 
Three-dimensional second order solid elements with reduced integration(C3D20R) were also used to model the ballast.

\subsubsection{The rail track}

The rails on the Bothnia line (Botniabanan) which Banafjäl bridge is located on, are continuous welded and have a cross section of UIC 60(Botniabanan (2010) and Thiebault et al. (2013)). The UIC 60 cross section was approximated by an I-beam cross section. The properties of the UIC 60 rail section is given in the table (2.1) and the figure (2.2).

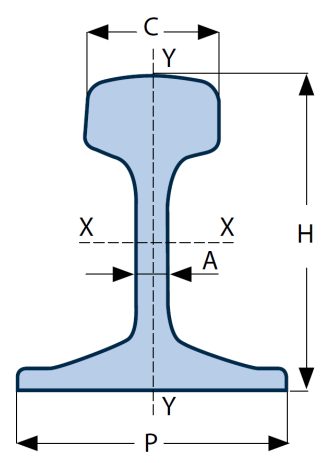

Figure 2.2: UIC 60 rail cross section(Banverket-b (1998) and Tata Steel (2010))

Table 2.1: Properties of the UIC 60 rail section (Figure 2.2)

\begin{tabular}{lc}
\hline Measure & Value \\
\hline Section weight $\mathrm{kg} / \mathrm{m}$ & 60.21 \\
Rail height(H) $\mathrm{mm}$ & 172.00 \\
Head width(C) $\mathrm{mm}$ & 72.00 \\
Web thickness(A) $\mathrm{mm}$ & 16.50 \\
Foot width(P) $\mathrm{mm}$ & 150.00 \\
Moment of inertia(Ixx) $\mathrm{cm}^{4}$ & 3038.30 \\
Moment of inertia(Iyy) $\mathrm{cm}^{4}$ & 512.30 \\
\hline
\end{tabular}

The two rails rest on the concrete sleepers. The spacing of the rails are $1.585 \mathrm{~m}$ and the longitudinal spacing between sleepers is $0.65 m$ (Banverket-a, 2008). The concrete sleepers were modeled as beams with rectangular cross sections of $0.2 m \times$ $0.3 \mathrm{~m}$ and the length of $2.6 \mathrm{~m}$.

The rails and sleepers were assumed to be rigidly connected. Thus the elastic behavior and the damping effect of the rail-sleeper connections were neglected.

The 3-node quadratic beam in space (B32) elements were used to model both the rails and the sleepers. 


\subsubsection{Materials}

All of the materials that the bridge is made of and the ballast were assumed to be linear elastic materials. The material properties used in the FEM is given in table $(2.2)$

Table 2.2: Material properties used in the FEM of Banafjäl bridge

\begin{tabular}{lccc}
\hline Material/Property & Young's modulus $(\mathrm{GPa})$ & Poisson's ratio & Density $\left(\mathrm{kg} / \mathrm{m}^{2}\right)$ \\
\hline Steel & 210 & 0.3 & 7850 \\
Concrete Slab & 37 & 0.2 & 2300 \\
Concrete Sleepers & 32 & 0.2 & 2300 \\
Ballast (warm) & 0.2 & 0.2 & 1900 \\
Ballast (cold) & 1.4 & 0.2 & 1900 \\
\hline
\end{tabular}

\subsubsection{Damping}

There are different ways of defining the damping matrix in the numerical modeling. In the modal dynamic analysis, which performed in this study, the damping of each specific mode can be specified.

In the current study, it was assumed that the damping ratio of the study range of the modes was constant and equal to the damping ratio of the Banafjäl bridge.

The damping ratio of the Banafjäl bridge was determined based on the suggested values by Eurocode 1 (EN-1991-2, 2003) that presented in table(2.3). For the Banafjäl bridge that is a composite bridge with the length of $42 m$, it was assumed that $\zeta=0.5(\%)$.

Table 2.3: The lower limit of percentage of critical damping (\%) to be assumed for design purposes (EN-1991-2, 2003)

\begin{tabular}{lcc}
\hline Bridge Type & Span $\mathrm{L}<20 \mathrm{~m}$ & Span $\mathrm{L} \geq 20 \mathrm{~m}$ \\
\hline Steel and composite & $\zeta=0.5+0.125(20-L)$ & $\zeta=0.5$ \\
Prestressed concrete & $\zeta=1.0+0.07(20-L)$ & $\zeta=1.0$ \\
Filler beam and & $\zeta=1.5+0.07(20-L)$ & $\zeta=1.5$ \\
reinforced concrete & & \\
\hline
\end{tabular}

\subsection{Calibration}

The boundary conditions of the Banafjäl bridge FE model were modeled as a simply supported beam. The restriction of the supports were introduced to the ends of the bottom flange of the girders. Then the model was calibrated against the reference 
available data of the bridge. The available data was the measured frequency of the first and second bending and the first torsional modes of the bridge (see table 2.4). The simply supported model could not reproduce the measured frequencies and their corresponding modes correctly as the stiffness of the model was lower than the expected values. This could be the result of neglecting the continuity of the rail track over the bridge. Thus in order to reproduce the correct stiffness, an additional rotational stiffness at the supports was necessary.

The additional stiffness was introduce to the model by means of two more restrictions at the ends of the FE model. First a spring element with one fixed end, was connected to the both ends of each rail to simulate the continuous welded rail. The stiffness of the spring was equivalent to the axial stiffness of the rail(figure 2.3).

The second additional restriction was introduced to the model by assuming that the support restrictions were acting on specified surfaces on the lower flanges of the girders instead of only one point or one line (figure 2.3).

Furthermore, the stiffness of the concrete was assumed to be $37 \mathrm{GPa}$, that is slightly higher than the design value of the K40 (C32/40) concrete. This value, however is consistent with the values measured by Gonzales et al. (2013) for a similar bridge (i.e. Skidträsk bridge).

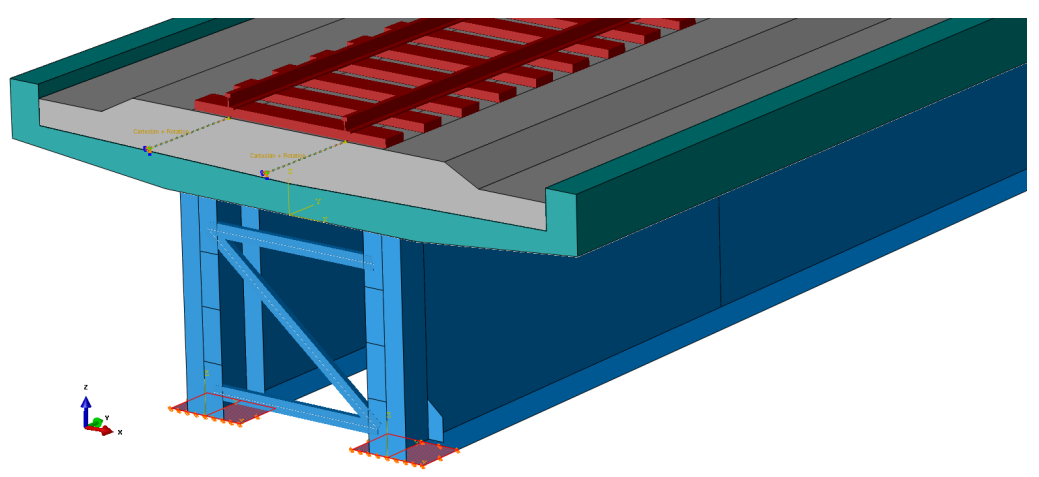

Figure 2.3: The acting surface of the supports and the the additional restriction to the end of the rails

Table 2.4 shows the final properties of the calibrated FE model of the Banafjäl bridge.

Table 2.4: The overall properties of the Banafjäl bridge FE model

\begin{tabular}{lccc}
\hline Variable & FE Model & Measured & Error $(\%)$ \\
\hline $1^{\text {st }}$ bending mode $(H z)$ & 3.2 & 3.3 & -3.0 \\
$1^{\text {st }}$ torsional mode $(\mathrm{Hz})$ & 3.5 & 3.4 & 2.9 \\
$2^{\text {nd }}$ bending mode $(\mathrm{Hz})$ & 9.6 & 9.5 & 1.1 \\
Mass $($ tonnes $/ \mathrm{m})$ & 16.1 & - & \\
\hline
\end{tabular}




\subsection{Dynamic analysis}

The dynamic analysis was performed utilizing modal superposition method under the defined dynamic load of passing HSLM-A train for speeds from 150 to $400 \mathrm{~km} / \mathrm{h}$. In the analysis based on the performed convergence analysis (see section 2.5), the modes with the frequency of up to $40 \mathrm{~Hz}$ and the time step of $\Delta t=0.001 \mathrm{~s}$ were used.

\subsubsection{Dynamic load}

According to Eurocode 1,(EN-1991-2, 2003) in the dynamic analysis of the simply supported railway bridges with the span length of higher than $7 m$, The High Speed Load Model ,HSLM-A, should be used. The specifications of HSLM-A train models are presented in figure (2.4) and table (2.5).

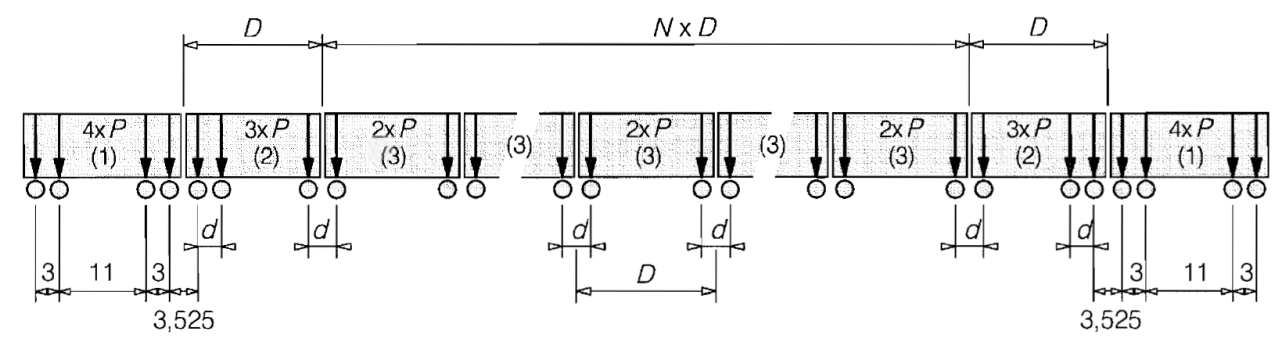

Figure 2.4: High Speed Load Model, HSLM-A, (EN-1991-2, 2003)

Table 2.5: High Speed Load Model, HSLM-A, (EN-1991-2, 2003)

\begin{tabular}{lcccc}
\hline $\begin{array}{l}\text { Universal } \\
\text { Train }\end{array}$ & $\begin{array}{c}\text { Number of } \\
\text { intermediate coaches }\end{array}$ & $\begin{array}{c}\text { coach } \\
\text { length } \\
D(\mathrm{~m})\end{array}$ & $\begin{array}{c}\text { Bogie } \\
\text { axle spacing } \\
d(\mathrm{~m})\end{array}$ & $\begin{array}{c}\text { Point } \\
\text { force } \\
P(\mathrm{kN})\end{array}$ \\
\hline HSLM-A1 & 18 & 18 & 2 & 170 \\
HSLM-A2 & 17 & 19 & 3.5 & 200 \\
HSLM-A3 & 16 & 20 & 2 & 180 \\
HSLM-A4 & 15 & 21 & 3 & 190 \\
HSLM-A5 & 14 & 22 & 2 & 170 \\
HSLM-A6 & 13 & 23 & 2 & 180 \\
HSLM-A7 & 13 & 24 & 2 & 190 \\
HSLM-A8 & 12 & 25 & 2.5 & 190 \\
HSLM-A9 & 11 & 26 & 2 & 210 \\
HSLM-A10 & 11 & 27 & 2 & 210 \\
\hline
\end{tabular}

In order to introduce the moving load due to the passing train over the bridge to the Abaqus, a Matlab code was developed to generate a suitable tabular amplitudes as an input for Abaqus for any given speed of HSLM-A trains. 
Then the dynamic response of the bridge under the effect of the passing HSLMA trains were evaluated by determining the maximum vertical displacement and vertical acceleration close to the mid-span of the bridge at the resonance speed of the trains. The resonance speed of the trains can be calculated as( $\mathrm{Li}$ and $\mathrm{Su}, 1999)$ :

$$
v=\frac{\omega}{2 \pi J} L_{v} \quad(J=1,2,3, \ldots)
$$

where $L_{v}$ is the vehicle (in this case the coach) length $(D)$ and $\omega$ is the fundamental frequency of the bridge. Finally the train with the highest response was selected to be utilized for the rest of the study, which in this case was the HSLM-A3 train (Figure 2.5). Thus, from the equation (2.1) the resonance speeds for the HSLM-A3 train are going to be :

$$
v=\left[\begin{array}{llllll}
231.6 & 115.6 & 77.2 & 57.9 & \ldots & ](\mathrm{km} / \mathrm{h})
\end{array}\right.
$$

which $231.6(\mathrm{~km} / \mathrm{h})$ will produce the higher response.
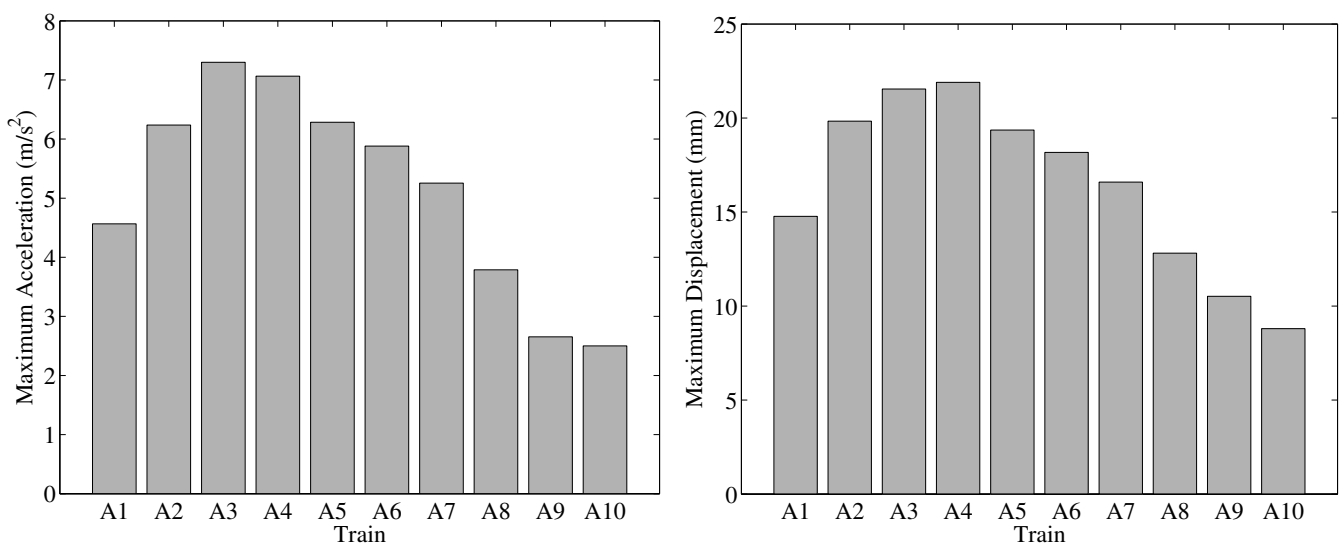

Figure 2.5: Maximum vertical acceleration (right) and maximum vertical displacement at the mid-span of the Banafjäl bridge due to passing HSLM-A trains

\subsection{Verification of the model}

Visual verification was carried out on the model to see if the model could reproduce the correct modes. The model was checked to see if the different parts of the model were moved in a reasonable way. Figure (2.6) shows the first and second bending mode of the FE model. 


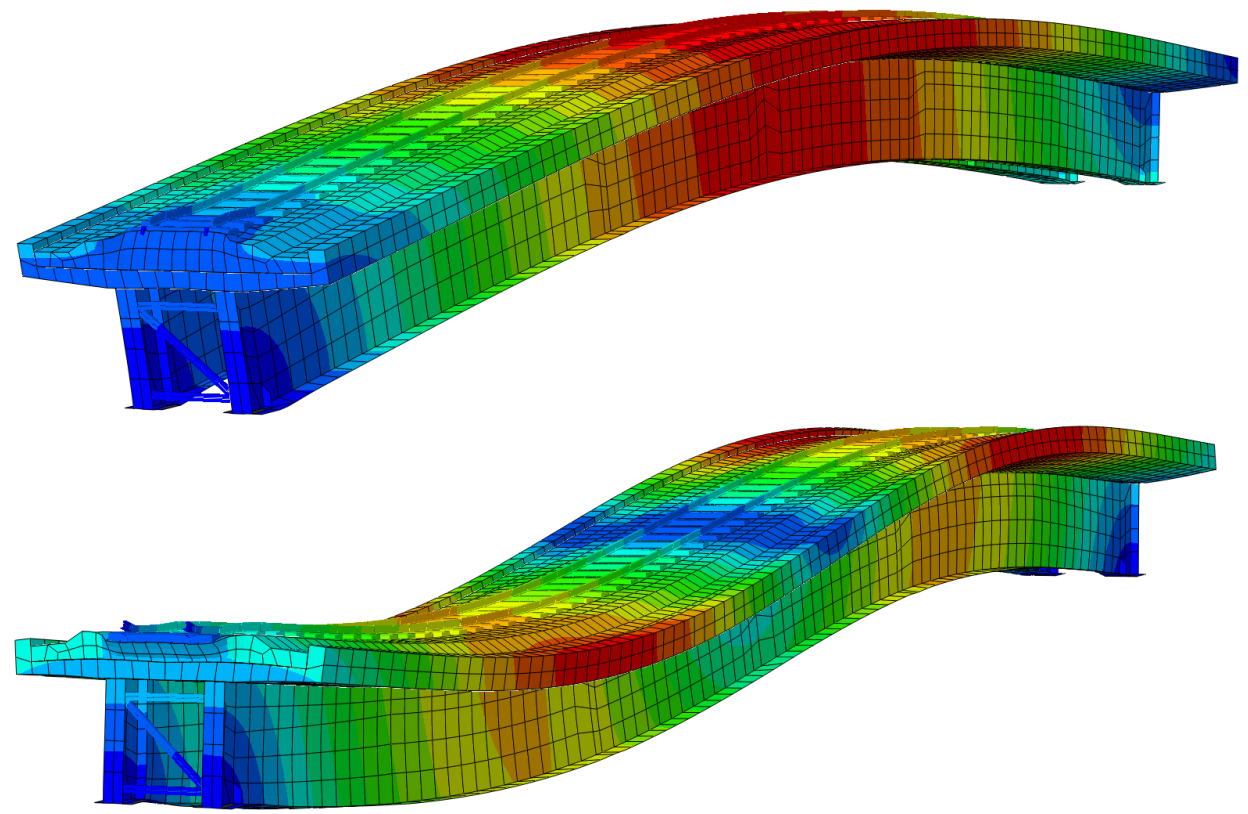

Figure 2.6: First and second bending modes of the Banafjäl bridge FE model

\subsection{Convergence analysis}

In order to have a time efficient model with an acceptable accuracy, it is necessary to perform a convergence analysis for the variables that affect the CPU time.

Convergence analysis was performed for several decisive variables including: mesh type; mesh size; time increment of analysis and number of modes used in the analysis. Since maximum vertical acceleration and maximum vertical displacement were the main focus of this study, they were assumed as the dependent variable in the convergence analysis.

\subsection{Tuned Mass Damper (TMD)}

To investigate the effect of the TMDs on the vibration control of the bridge, several different scenarios including different configurations and different TMD parameters were investigated.

Since the TMD is an additional mass attached to the bridge, too heavy TMD can have an adverse effect on the bearing capacity of the bridge. To avoid the significant undesired effect on the resistance of the bridge, lowest effective mass ratio of the TMD was of interest.

Therefore first several different mass ratio's (i.e. the ratio of the mass of TMD to the mass of the bridge) of a single tunes mass damper (STMD) were evaluated. Then a sufficient mass ratio that is large enough to have a great effect on the dynamic behavior of the bridge and small enough to avoid affecting the overall strength of 
the bridge negatively.

Considering the practical issues, the mass off the STMDs were selected based on the available TMDs in the market, for instance, in this study the TMDs provided by the Maurer company(MAURER, 2015) were considered.

A STMD can control only a single structural mode, therefore, a STMD that tuned to the most dominant will be the most effective (Rana and Soong, 1998). The most dominant mode of the Banafjäl bridge FE model was extracted using a puls like load acting near the mid-span. The most dominant mode was the first vertical bending mode with the frequency of $f_{1}=3.2 \mathrm{~Hz}$ (see figure 2.7).
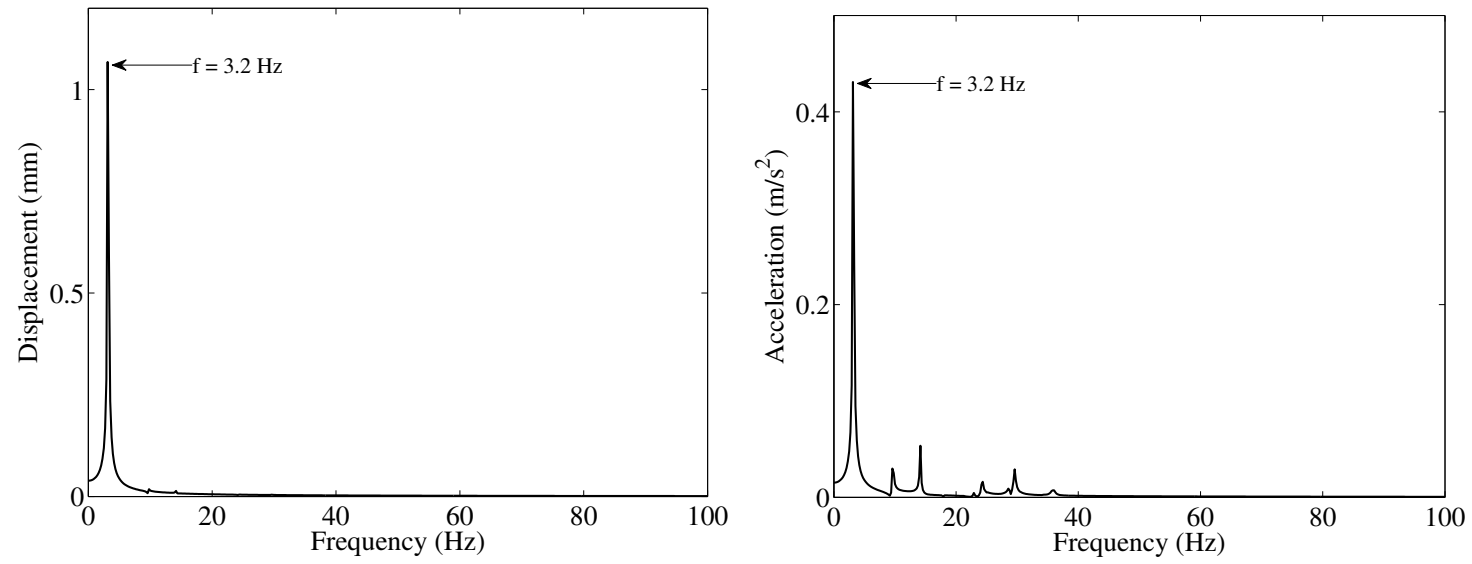

Figure 2.7: Fundumental frequency of the Banafjäl Bridge FE model

While the response frequency of the bridge will change under the load of the train $(\mathrm{Li}$ et al., 2003), in this study the fundamental frequency of the bridge without the train was utilized to estimate the TMD parameters to make the TMDs independent from the passing train.

The method suggested by Den Hartog (1956) described as equations (1.11, 1.12 and 1.13) in the section (1.2) was used to estimate the optimal parameters of the STMDs.

The STMD was attached to the mid-span of the FE model that is the anti-node of the first vertical bending mode where the amplitude is maximal and the STMD is the most effective(Rana and Soong, 1998).

The performance of the STMDs in suppressing the maximum acceleration and maximum displacement at the mid-span of the bridge were assessed under the the excitation induced by the HSLM-A3 train at the resonance speed(figure 2.8).

According to the Eurocode (EN-1990, 2002) the maximum vertical acceleration of the deck in the ballasted tracks shall not exceed $3.5 \mathrm{~m} / \mathrm{s}^{2}$, therefore only mass ratios that fulfill this condition were considered. Three different mass ratios that had an acceptable effect on the response of the bridge were selected for further investigations. Although in most of the previous studies (Hoang et al. (2008), Luu et al. (2012), Yang et al. (2015), Lin and Chen (2005), Wang et al. (2003), Lin et al. 

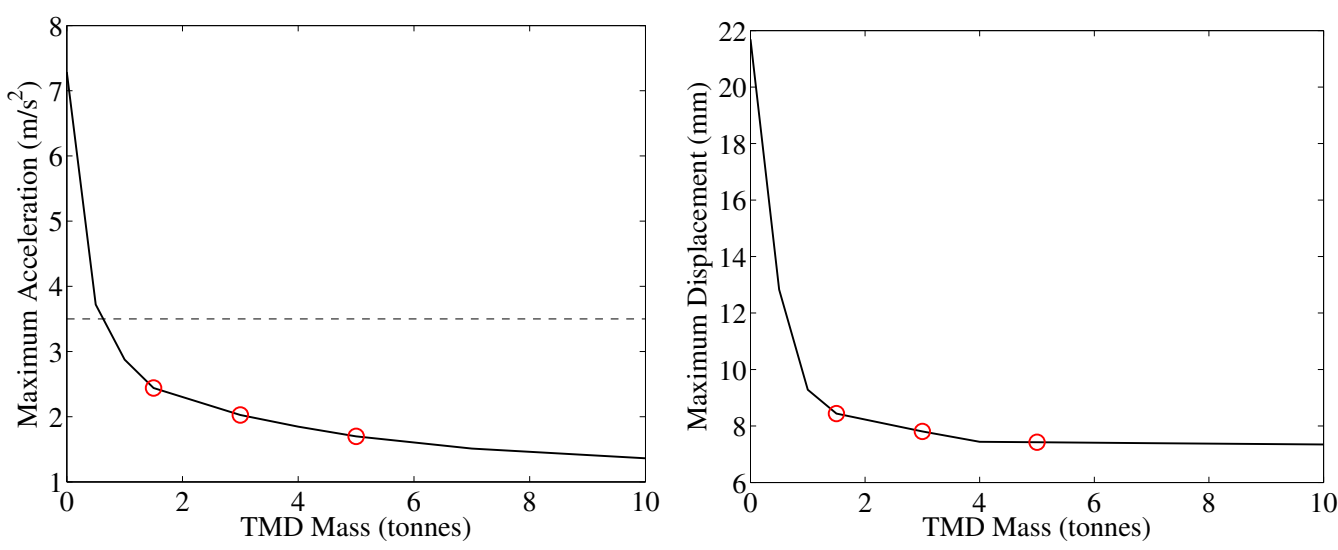

Figure 2.8: Effect of the mass ratio on the performance of the STMD in decreasing maximum acceleration (left) and maximum displacement (right) at the mid-span of the bridge

(1994) and Yau and Yang (2004a)) the mass ratios of equal or higher than $1 \%$ were selected, in this study based on the performance, all three selected mass ratios were below $1 \%$. The selected mass ratios were $\mu=0.22,0.44$ and 0.74 which correspond to the mass of $m=1.5,3$ and 5 tonnes.

After determining the suitable mass ratio, different configuration of the multiple tuned mass dampers (MTMD) were investigated.The number of TMDs in the MTMD configuration were selected as odd numbers $(N=1,3,5)$ that the middle one attached to the mid-span of the bridge and the other TMDs were attached with some deviation from the mid-span. Figure (2.9) shows the 5 TMDs attached to the bridge in a parallel configuration.

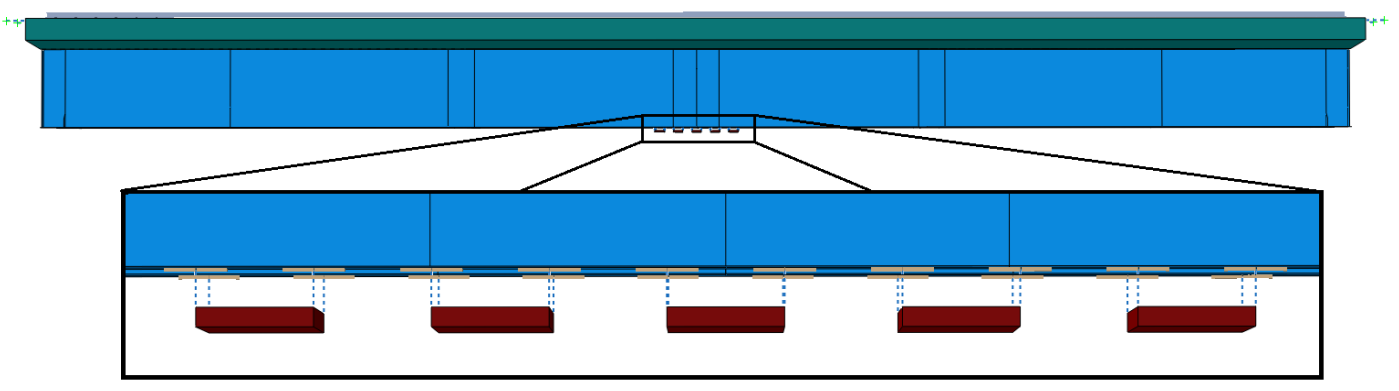

Figure 2.9: MTMDs attached to the mid-span of the bridge model

The STMD parameters were determined from equations ( 1.11 and 1.12 ). In the case of MTMDs, the frequency that MTMDs were tuned to, were uniformly distributed around their average natural frequency by $\Delta \omega$. The frequency of the $i^{\text {th }}$ TMD can be determined as( $\mathrm{Li}, \mathrm{Su}$, and Fan, 2005):

$$
\omega_{i}=\omega_{T}\left[1+\left(i-\frac{N+1}{2}\right) \frac{\Delta \omega}{N-1}\right] \quad(i=1,2,3, \ldots, N)
$$

where $\omega_{T}$ is the average frequency of the MTMDs that is in fact the optimal fre- 
quency of a STMD with the same mass ratio as the overall mass ratio of the MTMDs, $\mathrm{N}$ is the number of TMDs and $\Delta \omega$ is the frequency range of the MTMDs that can be determined as:

$$
\Delta \omega=\frac{\omega_{N}-\omega_{1}}{\omega_{T}}
$$

The values of frequency range were selected as $(\Delta \omega=5,10,15,20(\%))$. Parameters of the TMDs used in this study for $\Delta \omega=10(\%)$ are presented in table (2.6):

Table 2.6: Parameters of the STMD and MTMDs used in this study for $\Delta \omega=10(\%)$.

\begin{tabular}{|c|c|c|c|}
\hline $\begin{array}{l}\text { Number of } \\
\text { TMDs }\end{array}$ & $\begin{array}{c}\text { Total } \\
\text { weight } \\
m \text { (tonnes) }\end{array}$ & $\begin{array}{c}\text { Total } \\
\text { mass ratio } \\
\mu(\%)\end{array}$ & $\begin{array}{c}\text { Frequency ratios } \\
\text { of the TMDs } \\
\Delta \omega=10 \%\end{array}$ \\
\hline 1 & 1.5 & 0.22 & 0.9978 \\
\hline 1 & 3.0 & 0.44 & 0.9956 \\
\hline 1 & 5.0 & 0.74 & 0.9926 \\
\hline 3 & 1.5 & 0.22 & 0.94930 .99931 .0492 \\
\hline 3 & 3.0 & 0.44 & 0.94860 .99851 .0484 \\
\hline 3 & 5.0 & 0.74 & 0.94770 .99751 .0474 \\
\hline 5 & 1.5 & 0.22 & 0.94960 .97460 .99961 .02451 .0495 \\
\hline 5 & 3.0 & 0.44 & 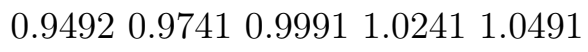 \\
\hline 5 & 5.0 & 0.74 & 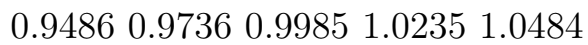 \\
\hline
\end{tabular}

In total, 31 different scenarios of the application of TMDs on the Banafjäl FE model were investigated. Then the scenario with the best performance and sufficient mass ratio was selected as the damping solution for the bridge.

\subsection{Sensitivity analysis}

One of the main problems of the application of the TMDs is detuning. Detuning can lead to a significant loss in the performance of the TMDs. Structural deterioration of the main structure, inadvertent change in the structure's dynamic characteristics, inaccurate determination of the dynamic characteristics of the main structure etc. can result in detuning of the TMDs(Roffel et al., 2011). Seasonal change in the dynamic properties of the of the railway bridges may happen due to freezing and ice forming that occurs in the the ballast(Gonzales et al., 2013).

Thus two scenarios were defined to investigate the detuning effect on the selected best case scenario. In the the first scenario the stiffness of the ballast was changed from $200 \mathrm{MPa}$ (warm season) to $1400 \mathrm{MPa}$ (cold season). This in fact increase the natural frequency by $5 \%$ from $3.2 \mathrm{~Hz}$ to $3.4 \mathrm{~Hz}$. Furthermore in the second scenario, The effect of the under-estimation of the fundamental frequency of the bridge was investigated. 



\section{Chapter 3}

\section{Analysis and results}

\subsection{Dynamic characteristics of the FE model}

Figure 3.1 shows the response at the mid-span of the Banafjäl bridge FE model under of the passing HSLM-A3 train.
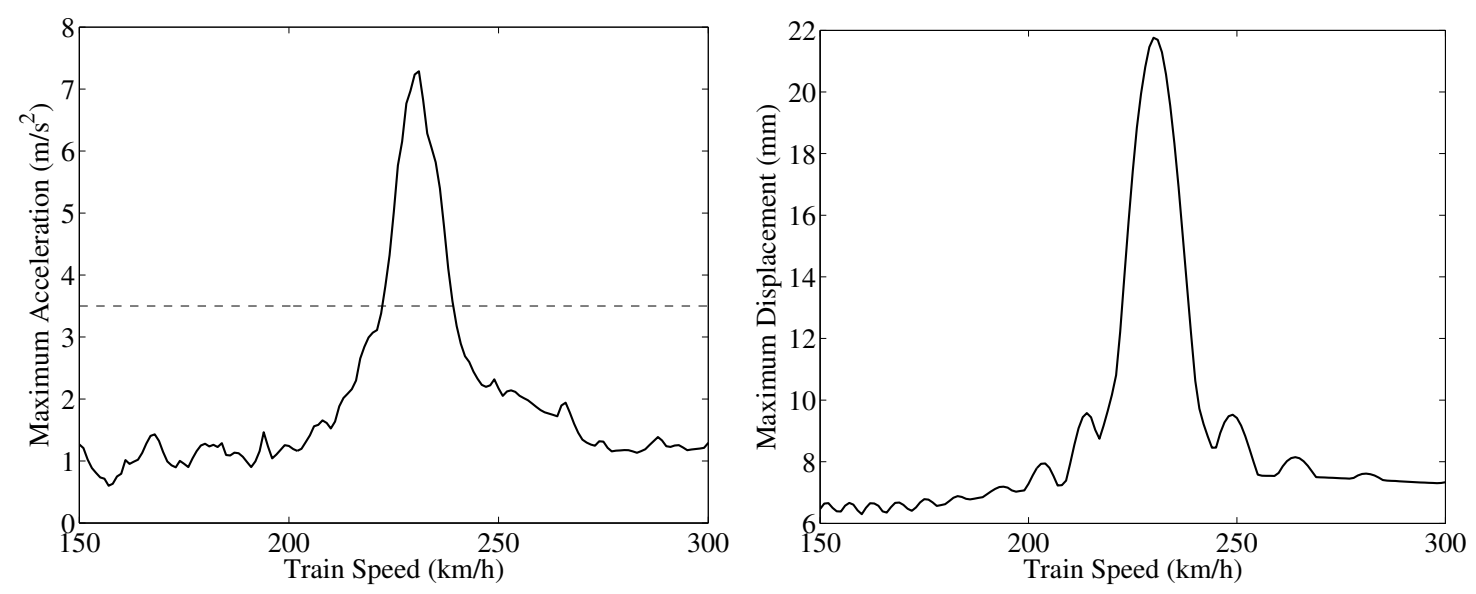

Figure 3.1: The response of the Banafjäl bridge FE model under the passing HSLMA3 train

As indicated in figure 3.1, in the speed range of 222 to $240 \mathrm{~km} / \mathrm{h}$, the maximum vertical acceleration (left) at the rails, exceeds the maximum permissible value (i.e. $3.5 \mathrm{~m} / \mathrm{s}^{2}$ ) showed by a dashed line. But the maximum vertical deflection (right) fulfill the necessary conditions and it is below the permissible limit that is: $L / 600=$ $70 \mathrm{~mm}$ (EN-1990, 2002).

Figure 3.1 also shows the bridge's response will reach the maximum at the train speed of $231(\mathrm{~km} / \mathrm{h})$ with the vertical acceleration peak of $7.3 \mathrm{~m} / \mathrm{s}^{2}$ and the vertical displacement peak of $22 \mathrm{~mm}$, which is the result of the resonance of the first vertical bending mode of the bridge.

The response of the bridge at the resonance speed of $231(\mathrm{~km} / \mathrm{h})$ is shown in figure 3.2 . 


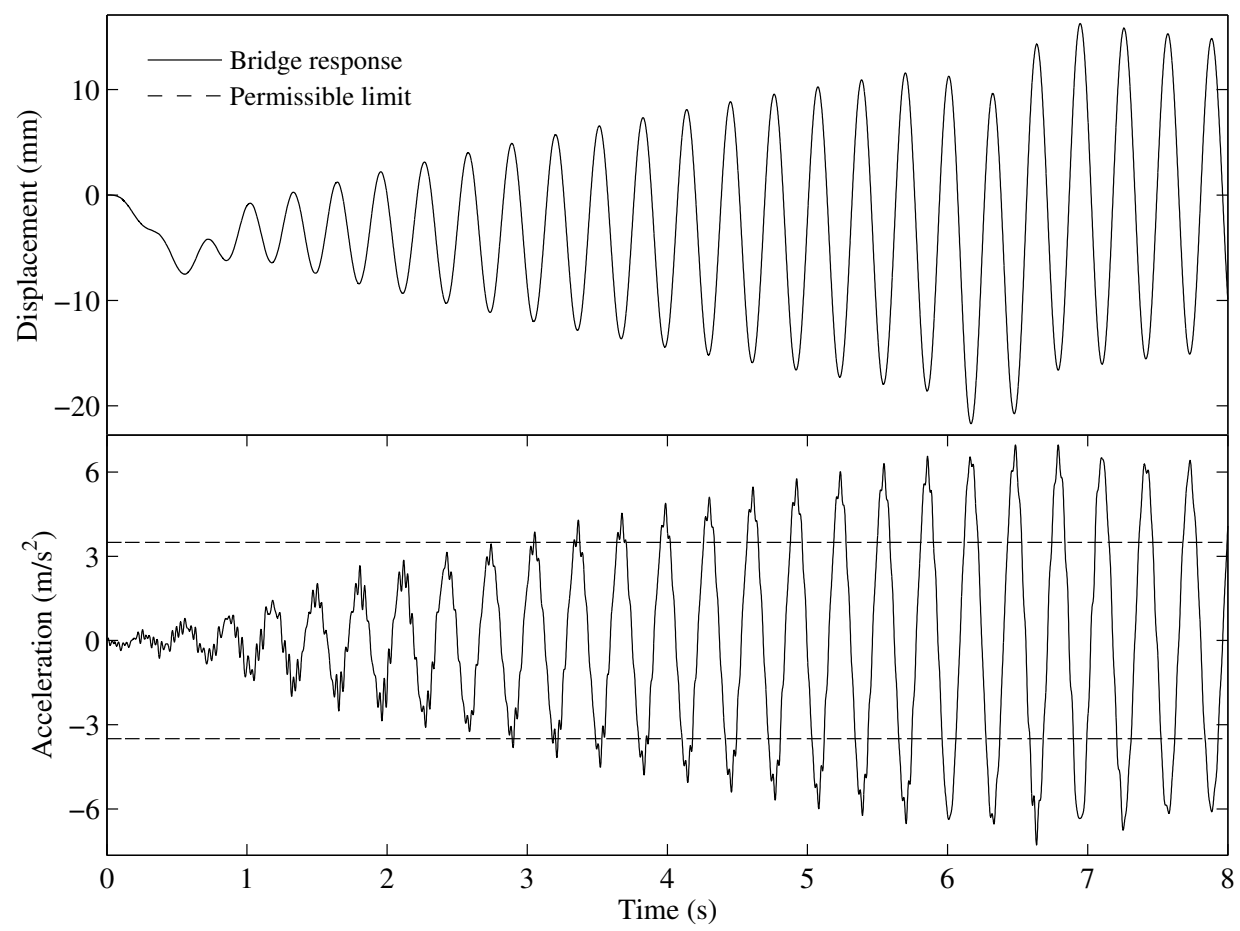

Figure 3.2: The response of the Banafjäl bridge FE model to the passing HSLM-A3 train at the resonance speed of $231(\mathrm{~km} / \mathrm{h})$

Thus, according to these results, the Banafjäl bridge does not fulfill the safety and comfort requirement conditions for a high speed train. Therefore it is necessary to improve the dynamic characteristics of the bridge using suitable actions. Application of TMDs could be one option to improve the dynamic response of the bridge, especially in the resonance condition.

\subsection{Application of TMDs}

Several different scenarios were defined and performed on the FE model of the Banafjäl bridge in order to investigate the effect of the TMDs on the response of the bridge under the dynamic load induced by a high speed train. Figure 3.3 presents the effect of a STMD on the response of the Banafjäl bridge FE model for different mass ratios of the STMD. The mass ratios are $0.22 \%, 0.44 \%$ and $0.74 \%$, which correspond to the mass of $1.5,3.0$ and 5.0 tonnes respectively. 

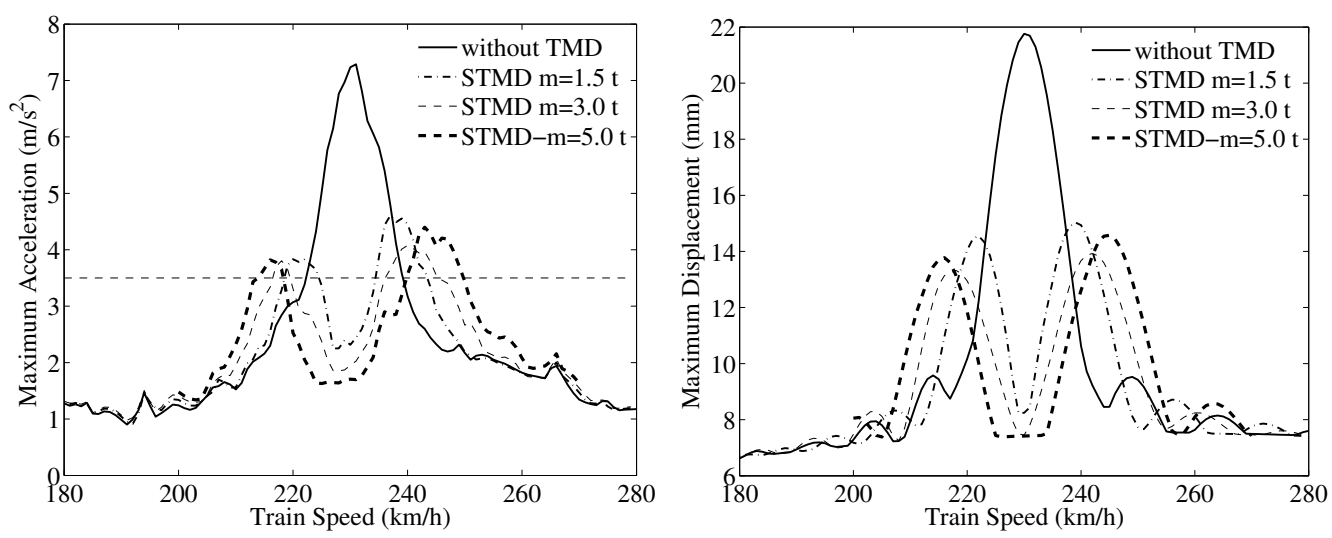

Figure 3.3: Effect of a STMD on the dynamic response of the Banafjäl bridge FE model with the mass ratios of $0.22 \%, 0.44 \%$ and $0.74 \%$, which correspond to the mass of $1.5,3.0$ and 5.0 tonnes respectively.

As indicated in figure 3.3, the STMD alters the dynamic response of the bridge from one peak resonance to two distinctive peak resonances. Whereby, the resonance peak amplitude decrease significantly. But the effect of the STMD disappear when the train speed deviate from resonance speed of $231 \mathrm{~km} / \mathrm{h}$ which STMD is tuned to.

All of the three mass ratios decrease the resonance peak of the maximum vertical displacement and acceleration at the resonance speed of $231 \mathrm{~km} / \mathrm{h}$ below the acceptable limit. But the two new response peak of the vertical acceleration, in the new bridge-STMD system are still unacceptable. The maximum vertical acceleration at the resonance speed of $231 \mathrm{~km} / \mathrm{h}$, has been reduced by $-67 \%,-72 \%$ and $-77 \%$ for the 1.5, 3 and 5 tonnes of STMD respectively. While the maximum vertical acceleration in the model with STMD, including the two new distinct peeks, is smaller than the model without STMD by only $-37 \%,-44 \%$ and $-40 \%$ for the $1.5,3$ and 5 tonnes of STMD respectively.

Thus, although even a small STMD can effectively decrease the the resonance peak, but the two new generated peaks still overshoot the limiting threshold even with a heavier STMDs.

In spite of that the higher mass ratio increase the effective range of the STMD, but still a STMD can not be a sufficient solution for vibration control of the Banafjäl bridge.

One solution to increase the effective range of the TMD, is that instead of using one large STMD that tuned to the resonance frequency, the total mass can be divided between several smaller TMDs that tuned to the resonance frequency with a small deviation. In other words, instead of one large concentrated mass, the total mass can be spread over a range of frequencies to produce a curve with several smaller peak instead of two large peaks.

Figure (3.4) shows the effectiveness of the MTMDs consist of three TMDs with the total mass ratios of $0.22 \%, 0.44 \%$ and $0.74 \%(\mathrm{~m}=1.5,3,5)$ and the total frequency range of $5 \%, 10 \%, 15 \%$ and $20 \%$. 

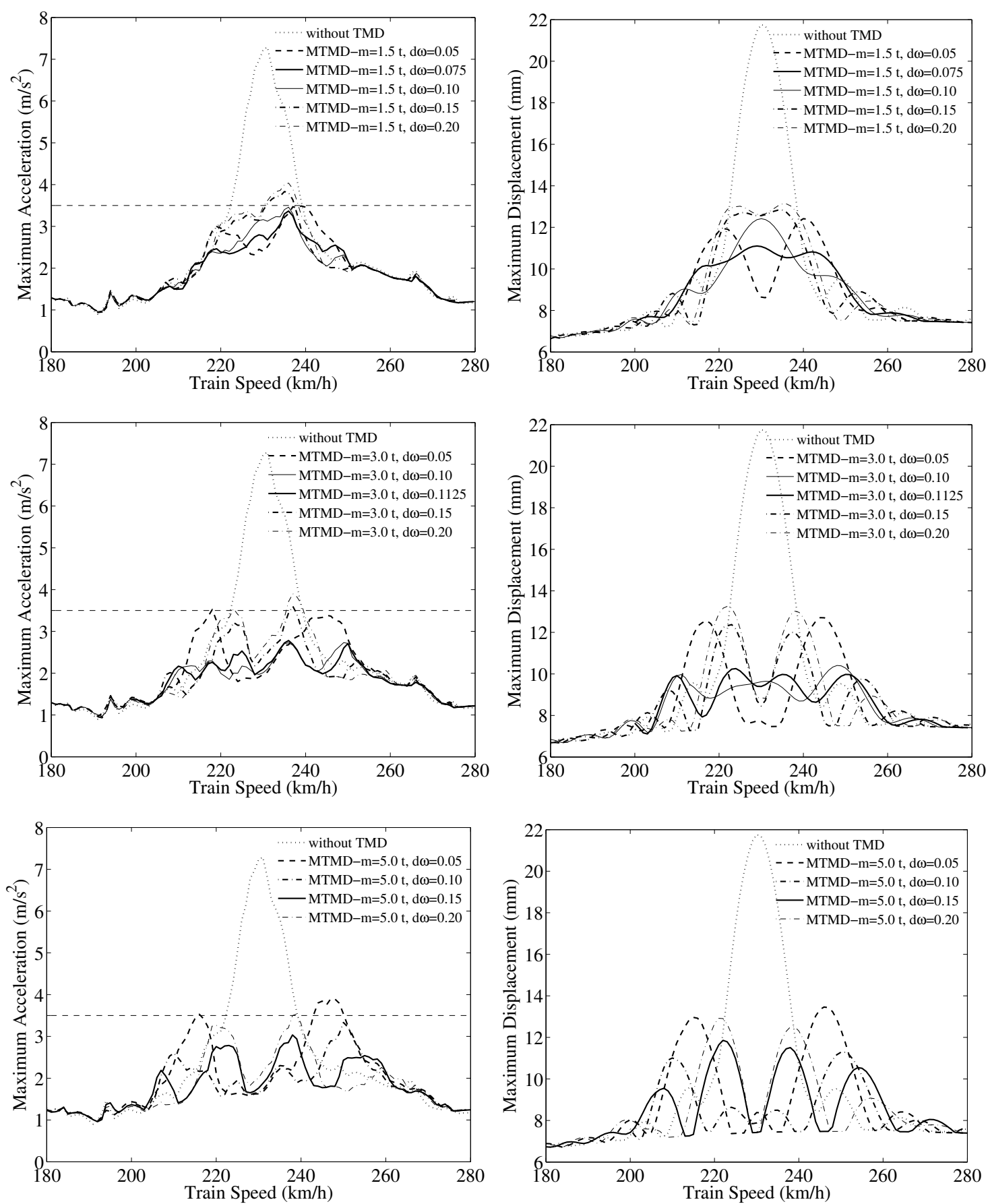

Figure 3.4: Effect of a MTMD consist of 3 TMDs on the dynamic response of the Banafjäl bridge FE model with the mass ratios of $0.22 \%$ (top row), $0.44 \%$ (middle row) and $0.74 \%$ (bottom row), which correspond to the mass of 1.5, 3.0 and 5.0 tonnes respectively, and with the total frequency deviation of $5 \%, 10 \%, 15 \%$ and $20 \%$.

The top row of the figure(3.4), indicate a set of scenarios with three TMDs and the mass ratio of $0.22 \%(\mathrm{~m}=1.5 \mathrm{t})$ and the frequency ranges of $5 \%, 7.5 \%, 10 \%, 15 \%$ and $20 \%$. As it can be seen there is a frequency range in which the MTMDs have the best performance relative to other frequency ranges. In the optimal frequency range 
the response curve of the vertical displacement is relatively flat, whereas the other frequency ranges have one or two distinctive larger peaks. This optimal frequency range is $7.5 \%$ for the mass ratio of $0.22 \%$. Furthermore, the maximum acceleration curve of the optimal frequency range produce the lowest acceleration that is below the maximum acceptable limit, while other frequency ranges often overshoot the threshold. This behavior is presented in figure (3.5).

Thus if the fundamental frequency of the bridge could be determined accurately, and the production procedure would carried out perfectly, this option could control the bridge's vibration effectively and with a lower cost. Despite that only three light TMDs have been used, but it still decrease the maximum vertical acceleration by $-54 \%$ and maximum vertical displacement by $-49 \%$.

Regardless of the sensitivity of this option, the limiting factor for this option is the high amplitude of the vibration of the MTMDs themselves, which needs a larger room for the oscillations. This may also cause fatigue in the MTMD spring and damping elements during the operation period.
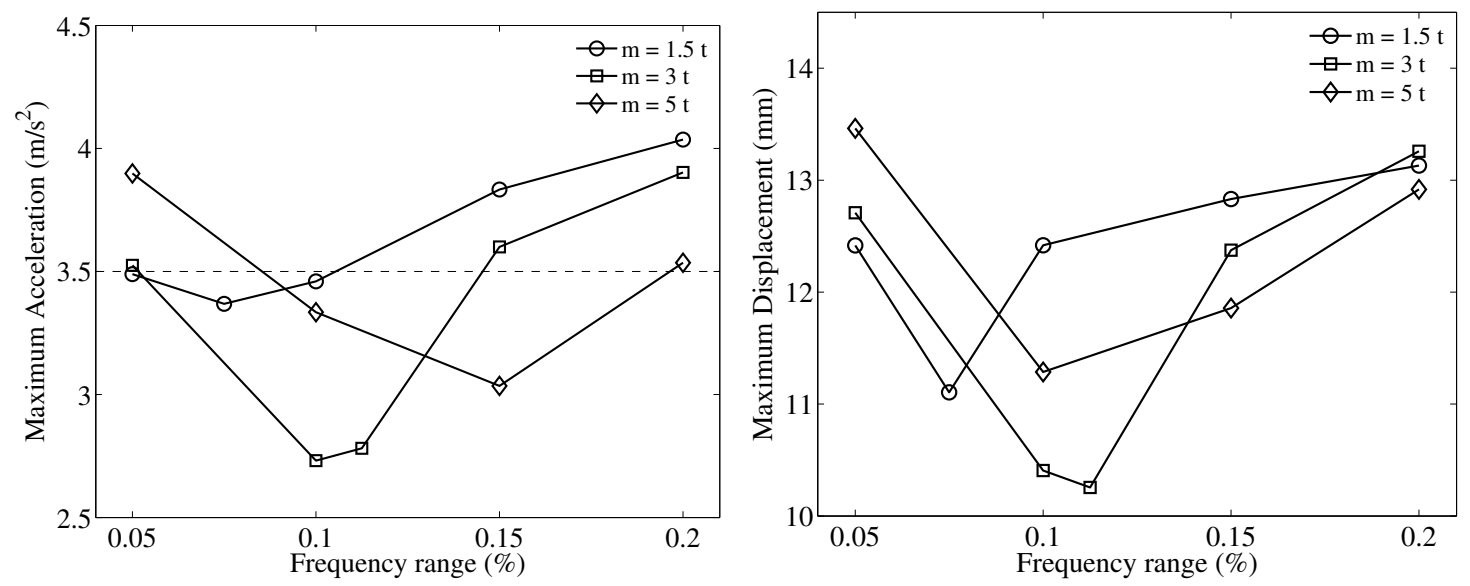

Figure 3.5: Relation between the frequency range of the MTMDs with three TMDs and the maximum response in the Banafjäl bridge FE model

The middle row of the figure 3.4 corresponds to the mass ratio of $0.44 \%$ with three TMDs, which indicate, by increasing the mass ration from $0.22 \%$ to $0.44 \%$ The MTMD system become even more efficient. The best performing scenario has the higher frequency range of $11.25 \%$. The maximum vertical acceleration and displacement have decreased by $-62 \%$ and $-53 \%$ respectively. Therefore while this option could be less economical relative to the previous option, but it has a better performance.

The lower row of the figure3.4 shows the set of scenarios with three 3 TMDs and the mass ratio of $0.74 \%$. In this set of the scenarios, despite that the maximum acceleration (left) reduced effectively, but the maximum displacement curve has four distinctive relatively large peaks which is far from the optimum performance. This indicate that three numbers of TMDs are not sufficient enough for this mass ratio, therefore, it can be seen that the higher mass ratio requires the higher numbers of TMDs to have an optimal performance. 
Figure 3.6 shows the scenarios with MTMDs consist of five TMDs in which, the upper row, the middle row and the bottom row correspond to the mass ratios of $0.22 \%$ to $0.44 \%$ and $0.74 \%$ respectively.
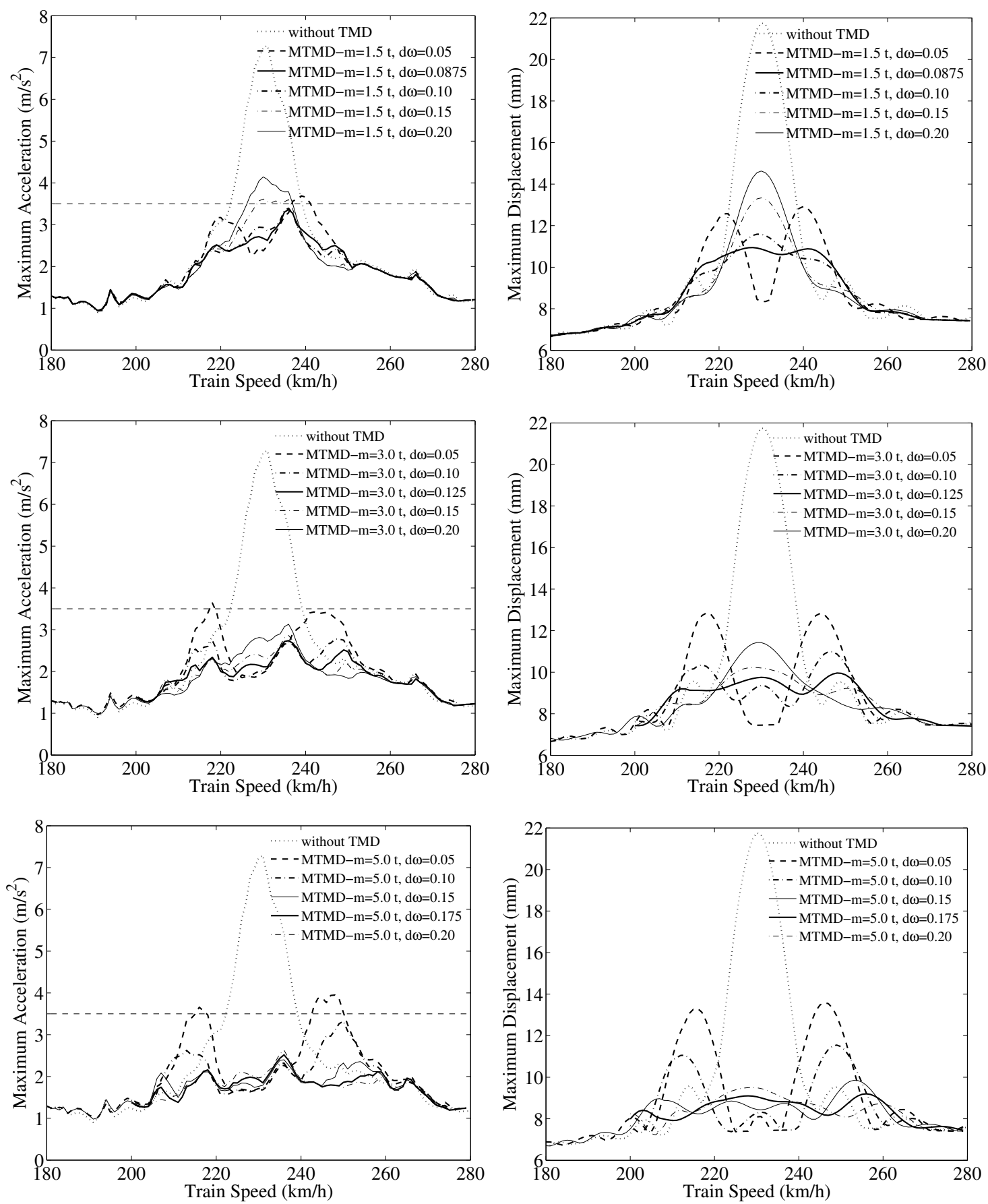

Figure 3.6: Effect of a MTMD consist of 5 TMDs on the dynamic response of the Banafjäl bridge FE model with the mass ratios of $0.22 \%$ (the top row), $0.44 \%$ (the middle row) and $0.74 \%$ (the bottom row), which correspond to the mass of 1.5, 3.0 and 5.0 tonnes and with the total frequency deviation of $5 \%, 10 \%, 15 \%$ and $20 \%$. 
As indicated in figure 3.6, the two systems of the MTMDs with three and five TMDs have a relatively similar behavior for the first two mass ratios of $0.22 \%$ and $0.44 \%$ (i.e. the top and the middle rows respectively).

However, the frequency range of the best performing scenarios of the MTMD system with five TMDs are slightly higher than the best performing scenarios of the MTMD systems that consist of three TMDs. In the MTMD systems that consist of five TMDs the optimal frequency ranges are $8.75 \%, 12.5 \%$ and $17.5 \%$ for the mass ratios of $22 \%, 44 \%$ and $75 \%$ (i.e. $\mathrm{m}=1.5,3$ and $5 \mathrm{t}$ ) respectively.

Figure 3.7 show the relation between the performance and the frequency range for three mass ratios of the MTMD system with five TMDs.
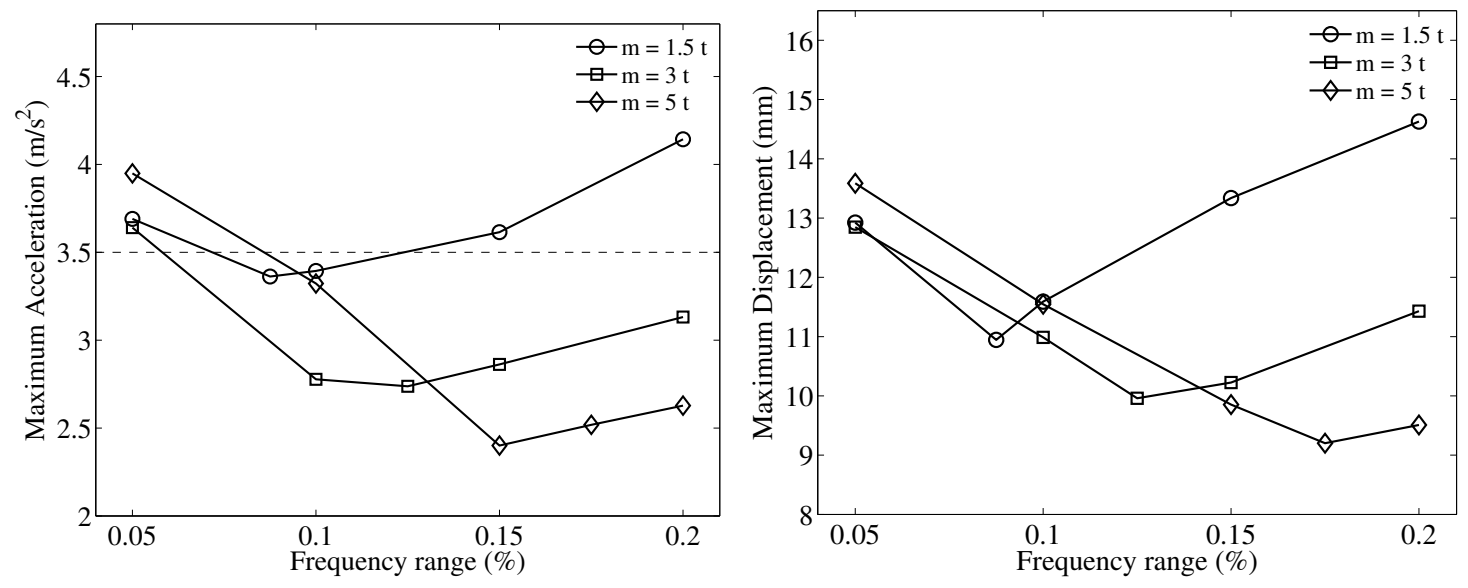

Figure 3.7: Relation between the frequency range of thr MTMDs and the maximum response in the Banafjäl bridge FE model

Figure 3.8 indicate the relation between the mass ratio and the optimum frequency range of the MTMDs.

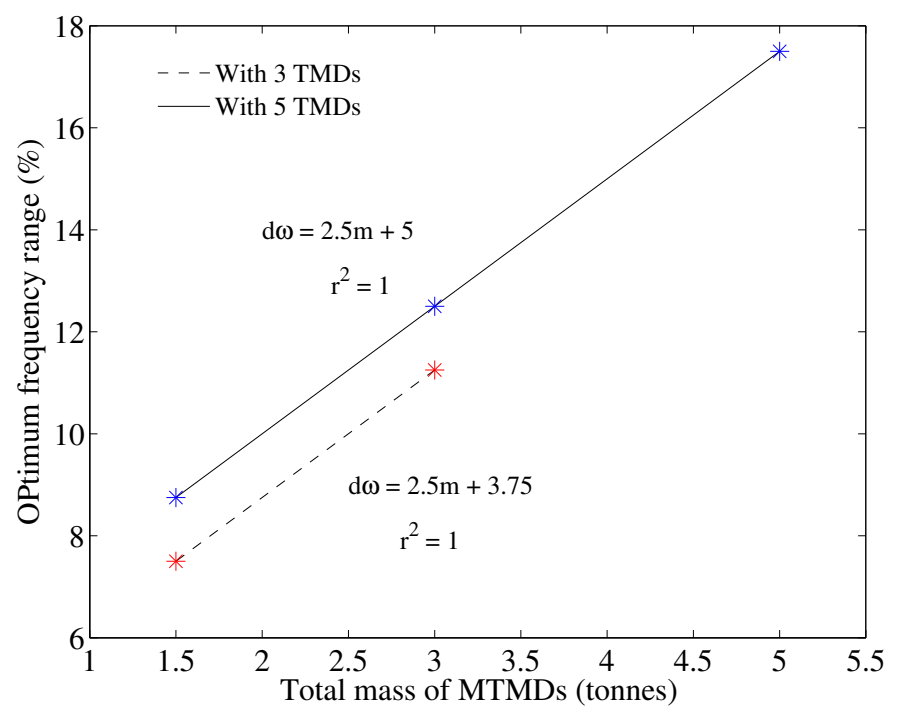

Figure 3.8: The relation between mass ratio and the optimum frequency range 
According to the figure 3.8, there is perfect linear relation between mass ratio and the optimum frequency range. Therefore the optimum frequency range for other mass ratios can be interpolated. Extrapolation for higher mass ratios however, is not recommended, since it may need higher numbers of TMDs in order to produce the optimum results.

A summery of the performance of the optimal scenarios (i.e. their ability to decrease the maximum acceleration and displacement in the mid-span of the Banafjäl bridge FE model) is presented in the table 3.1 .

Table 3.1: Summery of the best performing scenarios of using MTMDs on the Banafjäl bridge FE model.

\begin{tabular}{|c|c|c|c|c|}
\hline \multirow[b]{2}{*}{ Variable } & \multirow{2}{*}{$\begin{array}{c}\text { Number of } \\
\text { TMDs }\end{array}$} & \multicolumn{3}{|c|}{ Mass ratio } \\
\hline & & $0.22 \%$ & $0.44 \%$ & $0.74 \%$ \\
\hline \multirow{3}{*}{ Acceleration $\left(\mathrm{m} / \mathrm{s}^{2}\right)$} & Without TMDs & 7.29 & 7.29 & 7.29 \\
\hline & 3 TMDs & $3.37(-53.8 \%)$ & $2.78(-61.8 \%)$ & $3.03(-58.4 \%)$ \\
\hline & 5TMDs & $3.36(-53.9 \%)$ & $2.74(-62.5 \%)$ & $2.52(-65.5 \%)$ \\
\hline \multirow[t]{3}{*}{ Displacement $(m m)$} & Without TMDs & 21.8 & 21.8 & 21.8 \\
\hline & 3TMDs & $11.1(-49.0 \%)$ & $10.2(-52.9 \%)$ & $11.9(-45.51 \%)$ \\
\hline & 5TMDs & $10.9(-49.7 \%)$ & $10.0(-54.2 \%)$ & $9.2(-57.7 \%)$ \\
\hline
\end{tabular}

According to the results of the current study, all of the mass ratios effectively decrease the mid-span vibration of the Banafjäl bridge in the warm season (i.e. $\left.E_{\text {ballast }}=200 \mathrm{MPa}\right)$ and control the maximum acceleration below the acceptable limit of $3.5 \mathrm{~m} / \mathrm{s}^{2}$. However, the MTMD systems with 5 TMDs are preferred since, they are easier to handle due to the lighter weight and furthermore, they could be more tolerant against the possible failure of one of the TMDs.

\subsection{Sensitivity analysis}

The sensitivity of the MTMD systems with 5 TMDs, were investigated against the under estimation of the natural frequency of the bridge. Figure 3.9 indicates the maximum tolerance of the investigated MTMD systems with 5 TMDs to the underestimation of the dominant frequency without overshooting the maximum limt. 


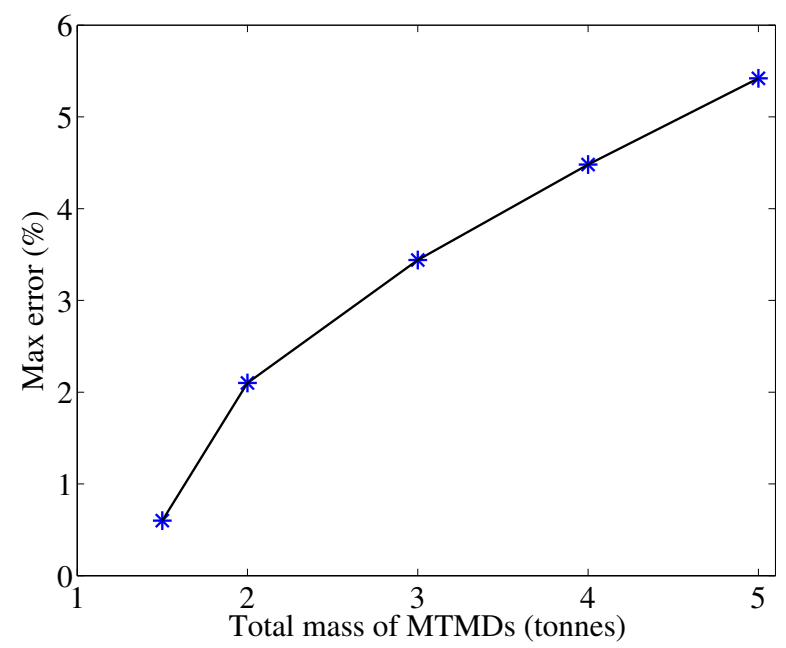

Figure 3.9: maximum tolerance of the MTMD systems with five TMDs for different mass ratios.

As shown in figure 3.9, the tolerance of the MTMD system will non-linearly increase with increase in the mass ratio which confirm the results of the previous studies (Rana and Soong, 1998). Figure 3.9 can be useful to determine the best suitable mass ratio based on the maximum acceptable error in the determination of the fundamental frequency of the bridge. It can be also used to estimate the suitable mass ratio with an acceptable performance in the cold season which is equivalent to approximately $5 \%$ underestimation of the natural frequency. Therefor according to the figure 3.9, the mass ratio should be at least $0.6 \%$ ( $m=4$ tonnes) for the MTMD system with 5-TMDs to perform effectively in both warm and cold season. Moreover, from figure 3.8, the optimal $d \omega$ for the mass ratio of $\mu=0.6 \%(m=4$ tonnes) is $d \omega=15 \%$. Figure (3.10) shows the effectiveness of the 5 MTMDs with the mass ratio of $\mu=0.6 \%(m=4$ tonnes $)$ and $d \omega=15 \%$ at the resonance speed of the HSLMA-A3 train.

Figure 3.11 indicate the the performance of the selected scenario $(\mu=0.6 \%, d \omega=$ $15 \%$ and $N=5$ ) that can perform in both warm and cold seasons. 


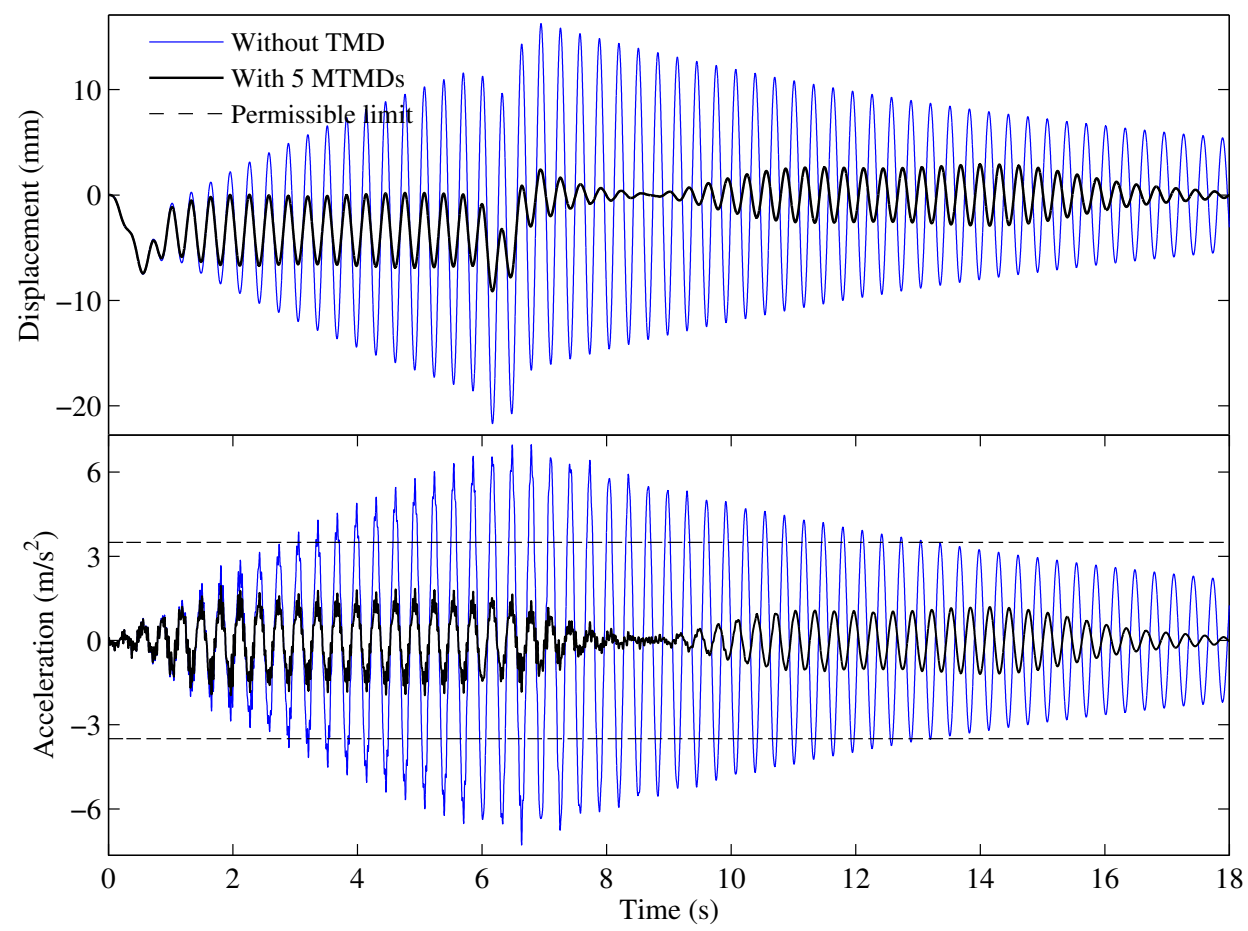

Figure 3.10: Effectiveness of the 5 MTMDs with the mass ratio of $\mu=0.6 \%(m=4$ tonnes) and $d \omega=15 \%$ at the resonance speed of the HSLMA-A3 train.
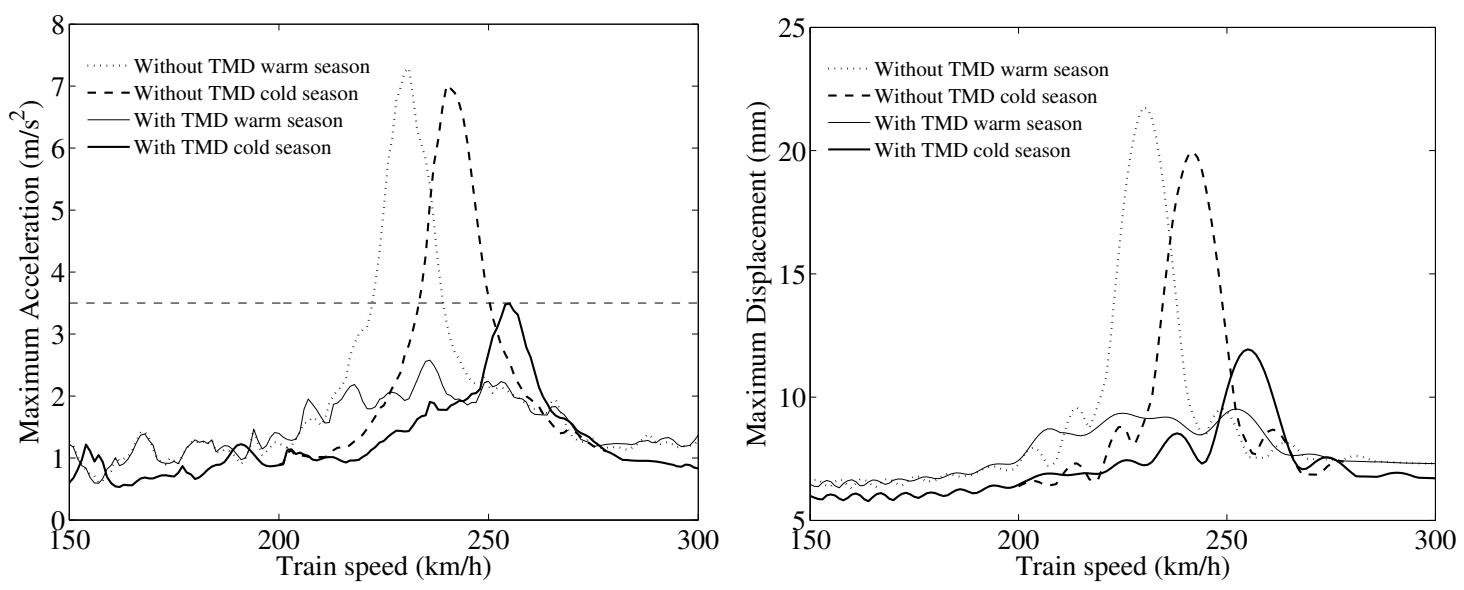

Figure 3.11: Performance of the selected MTMD system $(\mu=0.6 \%, d \omega=15 \%$ and $N=5$ ) in both warm and cold year

As presented in figure 3.11 A MTMD system with five TMDs and the mass of 4 tonnes can successfully control the vibration during the whole year. But there is no room for any further error or deviation from the tuned frequency. 


\section{Chapter 4}

\section{Conclusions and future studies}

\subsection{Conclusions}

In this study The Banafjäl bridge located on the Botniabanan in northern Sweden was studied. A 3D FE model of the bridge was developed using a commercial FE software, Abaqus and calibrated against the measured data of the bridge. The dynamic response of the bridge's FE model was investigated under the dynamic load of the passing HSLM-A train using modal dynamic analysis. Based on the results of this study The main conclusions based on the current work are presented in the following:

- Based on the results of this study, we concluded that in the modeling of the simply supported railway bridges with a continuous rails, the continuity of the rails has a significant effect on the stiffness of the bridge which cannot be neglected. This can be modeled by adding some additional rotational stiffness at the ends of the bridge.

- According to the results of the simulations, the Banafjäl bridge does not fulfill the Euorocode dynamic response condition, as the vertical acceleration exceeds the $3.5 \mathrm{~m} / \mathrm{s}^{2}$ limit for the speed range of the $220-240 \mathrm{~km} / \mathrm{h}$.

- A single tuned mass damper (STMD) can only control the vibration induced by train speeds close to the resonance speed, which the STMD is tuned to. Thus in this case, vertical acceleration can still exceed the permissible limit for speeds unequal to the resonance speed.

- Multiple tuned mass dampers (MTMDs) are preferred over STMDs, since MTMD can effectively flatten the response amplitude curve, whereby, effectively control the larger range of the speeds and frequencies.

- Among MTMDs the systems with higher numbers of TMDs are more desirable as handling lighter TMDs are easier and their performance is or tolerant against the failure of one or some of the TMDs. Higher numbers of TMDs, however, can be less economical. 
- Higher mass ratio of the MTMD system increase the frequency range of the operation and increase the tolerance of the system against detuning.

- According to the results of this study, a 4 tonnes MTMD system with 5 TMDs ( $\mu=0.6 \%$ and $d \omega=15 \%)$ attached to the mid-span of the Banafjäl bridge, can effectively control the resonance vibration of the bridge that induced by the HSLMA-A3 train during both warm and cold seasons.

\subsection{MTMD design procedure}

Based on the performed study, the following step-by-step instructions could be helpful in designing an MTMD system for a high-speed railway bridge that is susceptible to resonance, using a calibrated FE model:

1. Determine the worst case scenario of the external dynamic load between suggested train models in their resonance speed (see section 2.3.1).

2. Determine the most dominant mode and its frequency in the working speed range of the bridge using for instance a pulse load (see figure 2.7).

3. Attache a single TMD to the anti node of the dominant mode.

4. Tune the STMD to the dominant frequency using Den Hartog (1956) method (equations 1.11 and 1.12)

5. Evaluate the bridge-STMD system for different mass ratios under the passing selected train model at its resonance speed (see figure 2.8).

6. select three mass ratios that effectively control the resonant vibration of the bridge for further investigations using MTMDs (see figure 2.8).

7. Choose a suitable numbers of the TMDs in the MTMD system, as higher numbers of TMDs have a better performance but more costly.

8. Determine the optimal frequency range $(d \omega)$ by running the model for different frequency ranges ( see figures 3.4, 3.5, 3.6 and 3.7) and draw a relation between mass ratio and optimal $d \omega$ (see figure 3.8 ).

9. Evaluate the optimal MTMDs for their maximum tolerance against errors in the design parameters or detuning (e.g. underestimation of the dominant frequency), and draw a relation between the mass ratio and the maximum error that each MTMD system can tolerate (see figure 3.9).

10. Choose a maximum acceptable error in the design or maximum acceptable detuning, then, determine the suitable mass ratio and optimal $d \omega$ using relations generated at the steps 9 and 8 respectively. 


\subsection{Future studies}

As mentioned in the section 1.5, current work has some limitations due to assumptions have made in order to simplify the problem. Thus any more profound studies that could eliminate any or some of the mentioned limitations could be a suggestion for further studies:

- Investigate the effect of horizontal curvature of the bridge and the transverse slope of the ballast and whereby investigate the effects of torsional modes.

- Investigate the effect of possible non-linearity in the dynamic response of the bridge.

- Investigate the effect of foundation an bearings on the dynamic response of the bridge.

- Investigate the effect of suspension system of the vehicle on the total responce of the bridge. 



\section{Bibliography}

Amezquita-Sanchez, J. P., Dominguez-Gonzalez, A., Sedaghati, R., de Jesus Romero-Troncoso, R., Osornio-Rios, R. A., 2014. Vibration control on smart civil structures: A review. Mechanics of Advanced Materials and Structures 21 (1), $23-38$.

Banverket-a, 2008. Broregler för nybyggnad - bv bro, utgåva 9. Banverket.

Banverket-b, 1998. Räler, krav på nya och begagnade. Banverket.

Botniabanan, 2010. Environmental product declaration for the railway infrastructure on the bothnia line. Botniabanan AB.

Chopra, A. K., 2012. Dynamics of Structures: Theory and Applications to Earthquake Engineering, 4th Edition. Prentice Hall, Englewood Cliffs, New Jersey, USA.

Den Hartog, J. P., 1956. Mechanical Vibrations. McGraw-Hill Book Company, New York, USA.

Domaneschi, M., Martinelli, L., Po, E., 2015. Control of wind buffeting vibrations in a suspension bridge by tmd: Hybridization and robustness issues. Computers \& Structures 155, 3 - 17, cIVIL-COMP.

EN-1990, 2002. Eurocode : Basis of structural design. The European Union Per Regulation 305/2011.

EN-1991-2, 2003. Eurocode 1: Actions on structures - part 2: Traffic loads on bridges. The European Union Per Regulation 305/2011.

EN-1993-1-1, 2005. Eurocode 3: Design of steel structures - part 1-1: General rules and rules for buildings. The European Union Per Regulation.

Gillet, G., 2010. Simply supported composite railway bridge: a comparison of ballasted and ballastless track alternatives : Case of the banafjäl bridge. Master's thesis, KTHKTH, Structural Design and Bridges, The KTH Railway Group.

Gonzales, I., Ülker Kaustell, M., Karoumi, R., 2013. Seasonal effects on the stiffness properties of a ballasted railway bridge. Engineering Structures 57, $63-72$.

Gu, M., Chang, C., Wu, W., Xiang, H., 1998. Increase of critical flutter wind speed of long-span bridges using tuned mass dampers. Journal of Wind Engineering and Industrial Aerodynamics 73 (2), 111 - 123. 
Gutierrez Soto, M., Adeli, H., 2013. Tuned mass dampers. Archives of Computational Methods in Engineering 20 (4).

Hoang, N., Fujino, Y., Warnitchai, P., 2008. Optimal tuned mass damper for seismic applications and practical design formulas. Engineering Structures 30 (3), 707 715 .

Honda, A., Shiraishi, N., Matsumoto, M., Fuse, Y., Sumi, K., Sasaki, N., 1993. Aerodynamic stability of kansai international airport access bridge. Journal of Wind Engineering and Industrial Aerodynamics 49 (1-3), 533 - 542.

Igusa, T., Xu, K., 1994. Vibration control using multiple tuned mass dampers. Journal of Sound and Vibration 175 (4), 491 - 503.

Kareem, A., Kline, S., 1995. Performance of multiple mass dampers under random loading. Journal of Structural Engineering 121 (2), 348-361.

Kwon, H.-C., Kim, M.-C., Lee, I.-W., 1998. Vibration control of bridges under moving loads. Computers \& Structures 66 (4), 473 - 480.

Li, J., Su, M., , Fan, L., 2003. Natural frequency of railway girder bridges under vehicle loads. Journal of Bridge Engineering 8 (4), 199-203.

Li, J., Su, M., 1999. The resonant vibration for a simply supported girder bridge under high-speed trains. Journal of Sound and Vibration 224 (5), 897 - 915.

Li, J., Su, M., Fan, L., 2005. Vibration control of railway bridges under high-speed trains using multiple tuned mass dampers. Journal of Bridge Engineering 10 (3), $312-320$.

Lin, C., Hu, C., Wang, J., Hu, R., 1994. Vibration control effectiveness of passive tuned mass dampers. Journal of the Chinese Institute of Engineers 17 (3), 367376.

Lin, C., W.-J., Chen, B., 2005. Train-induced vibration control of high-speed railway bridges equipped with multiple tuned mass dampers. Journal of Bridge Engineering 10 (4), 398-414.

Lin, Y.-Y., Cheng, C.-M., Lee, C.-H., 2000. A tuned mass damper for suppressing the coupled flexural and torsional buffeting response of long-span bridges. Engineering Structures 22 (9), 1195 - 1204.

Luu, M., Zabel, V., Könke, C., 2012. An optimization method of multi-resonant response of high-speed train bridges using \{TMDs\}. Finite Elements in Analysis and Design 53, $13-23$.

Mai, L., 2014. Structural control systems in high-speed railway bridges. Ph.D. thesis.

MAURER, 2015. Maurer söhne.

URL http://www.maurer.eu/en.html 
Michalakis C Constantinou, Tsu T Soong, G. F. D., 1998. Passive energy dissipation systems for structural design and retrofit. Multidisciplinary Center for Earthquake Engineering Research.

Rana, R., Soong, T., 1998. Parametric study and simplified design of tuned mass dampers. Engineering Structures 20 (3), 193 - 204, structural Control.

Roffel, A., Lourenco, R., Narasimhan, S., Yarusevych, S., 2011. Adaptive compensation for detuning in pendulum tuned mass dampers. Journal of Structural Engineering 137 (2), 242-251.

Saaed, T. E., Nikolakopoulos, G., Jonasson, J.-E., Hedlund, H., 2015. A state-ofthe-art review of structural control systems 21 (5), 919-937.

Scandiaconsult, 2002. The banajäl bridge drawings. Scandiaconsult AB.

Tata Steel, R., 2010. Rail technical guide. Tata Steel.

URL http://www.tatasteelrail.com/static_files/StaticFiles/Rail/ Rail/20Technical/20Guide/20EN.pdf

Thiebault, V., Du, G., Karoumi, R., 2013. Design of railway bridges considering life-cycle assessment. Proceedings of the Institution of Civil Engineers: Bridge Engineering 166 (4), 240-251, cited By 2.

Wang, J., Lin, C., Chen, B., 2003. Vibration suppression for high-speed railway bridges using tuned mass dampers. International Journal of Solids and Structures $40(2), 465-491$.

Xia, H., Zhang, N., 2005. Dynamic analysis of railway bridge under high-speed trains. Computers and Structures 83 (23-24), 1891 - 1901.

Yamaguchi, H., Harnpornchai, N., 1993. Fundamental characteristics of multiple tuned mass dampers for suppressing harmonically forced oscillations. Earthquake Engineering and Structural Dynamics 22 (1), 51-62.

Yang, F., Sedaghati, R., Esmailzadeh, E., 2015. Optimal design of distributed tuned mass dampers for passive vibration control of structures. Structural Control and Health Monitoring 22 (2), 221-236.

Yau, J., Yang, Y., 2004a. Vibration reduction for cable-stayed bridges traveled by high-speed trains. Finite Elements in Analysis and Design 40 (3), 341 - 359.

Yau, J.-D., Yang, Y.-B., 2004b. A wideband $\{$ MTMD $\}$ system for reducing the dynamic response of continuous truss bridges to moving train loads. Engineering Structures 26 (12), 1795 - 1807. 



\section{Appendix A}

\section{Python code}

In order to run the the FE model of the bridge for different defined scenarios, a python code was developed to run the model using the input file generated by Abaqus:

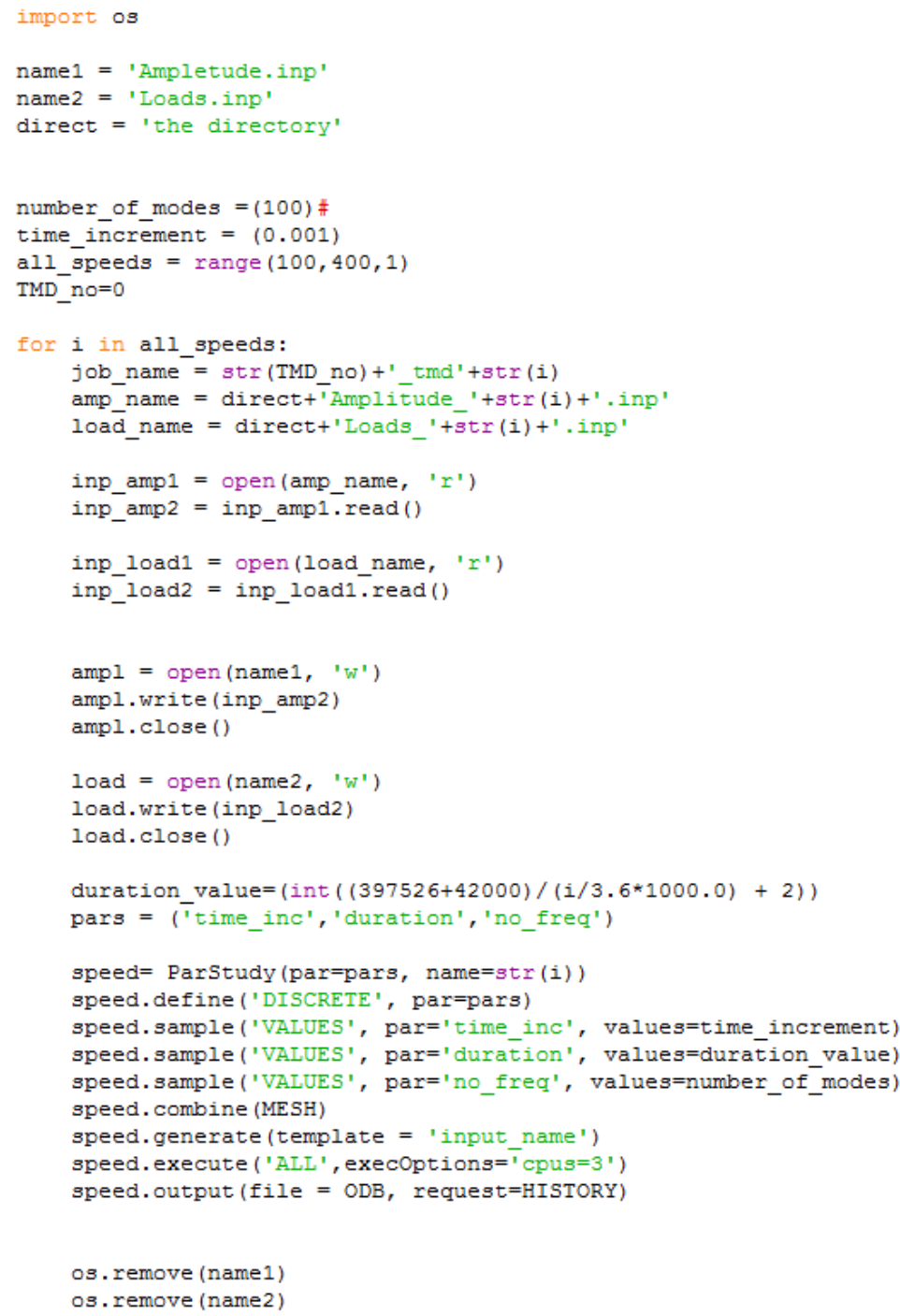


Then, another python code was developed to extract the desired data from the generated Abaqus ODB file:

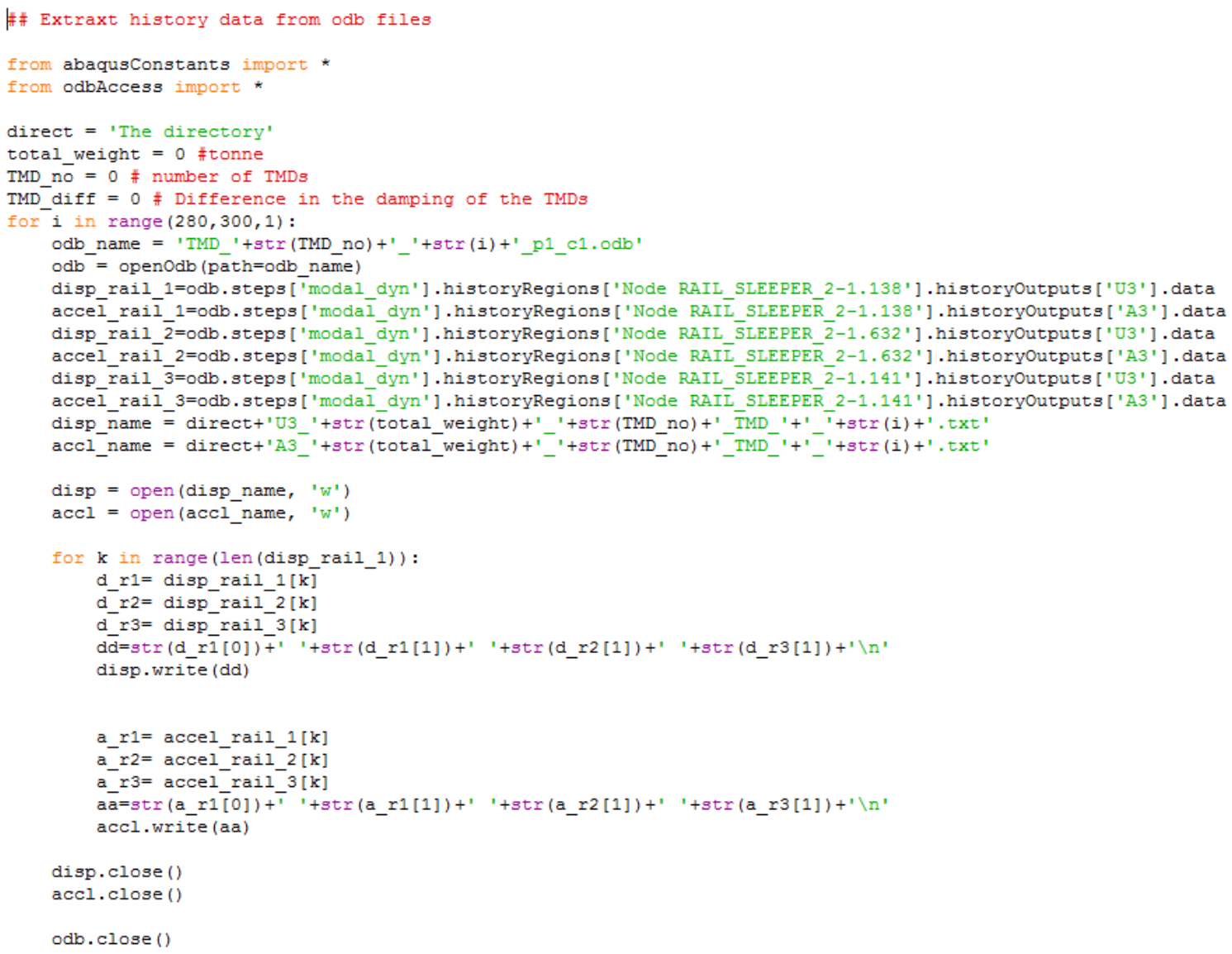


Appendix B

\section{Extended summary}




\section{Vibration Control of a High-Speed Railway Bridge Using Multiple Tuned Mass Dampers}

\section{B.1 Abstract}

In the current thesis, the Banafjäl bridge located on the Bothnia line (Botniabanan) in northern Sweden was studied. The bridge is a $40 \mathrm{~m}$ long composite ballasted high-speed railway bridge. A 3D FE model of the bridge was developed using a commercial FE software, Abaqus. The FE model was calibrated against the measured data of the bridge. The dynamic response of the bridge's FE model was investigated under the dynamic load of the passing HSLM-A train using modal dynamic analysis. The vertical acceleration induced by excitation of the passing train exceeded the permissible limit of $3.5 \mathrm{~m} / \mathrm{s}^{2}$ for the speed range of $220-240 \mathrm{~km} / \mathrm{h}$. Thus, damping solutions using multiple tuned mass dampers (MTMDs) were investigated. According to the results of this study, a 4 tonnes MTMD system consist of 5 parallel TMDs attached to the mid-span of the bridge could effectively control the undesired vibration of the bridge. The suggested solution could account for the changes in the stiffness of the bridge caused by freezing and ice forming in the ballast.

Keywords: Tuned mass dampers, Dynamic analysis, high-speed railway bridge, Banafjäl bridge

\section{B.2 Introduction}

High speed railway systems have become an important part of the national economy in developed countries. Therefore there is a growing demand to increase the permissible axle load and the speed in the existing railways. Dynamic response of the bridge is one of the limiting components in bridges especially in the High speed railway tracks (Xia and Zhang, 2005).

In this study, the dynamic response of an existing high-speed railway bridge, is going to be investigated. In the case of unsatisfying response of the bridge, effectiveness of an external damping system will be investigated and a suitable damping solution using structural control system will be proposed.

Structural control systems or motion control systems are additional systems added to the main structure that can reduce the response of the main structure subjected to a dynamic load e.g. seismic load, wind load and traffic load.

Passive control systems utilize the energy produced by the motion of the primary structure and thereby dissipate a portion of the input energy from the dynamic 
load. Since theses control systems produce higher damping force when the dynamic response of the main structure is higher, they have been considered as smart control systems in the past. (Amezquita-Sanchez et al. (2014), Saaed et al. (2015), Michalakis C Constantinou (1998) and Mai (2014)).

Tuned Mass Damper (TMD) is among the oldest types of passive control systems. It is invented by Frahm in 1909 .

A simple undamped structure with an attached TMD behave like a simple two degree of freedom system without damping(see figure 1.1).

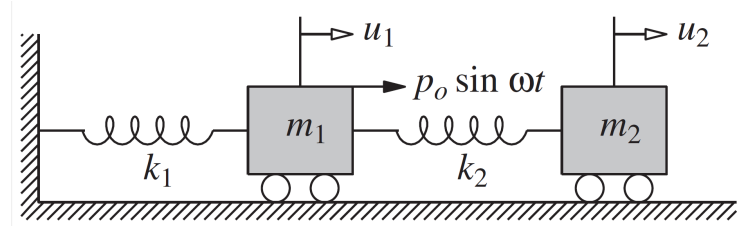

Figure B.1: A two DOF system(Chopra, 2012)

In such system by tuning the second mass to the frequency of the external load, the undesirable vibration of the first mass (primary structure) can be prevented. Thus, TMDs can be highly effective in suppressing the resonance response due to the external force.

Den Hartog (1956) suggested a method to determine the optimal parameters of a damped TMD that attached to an undamped SDOF system, to minimize the steady state response of the main mass subjected to a harmonic load as following:

$$
\begin{gathered}
f=\frac{1}{1+\mu} \\
\zeta=\sqrt{\frac{3 \mu}{8(1+\mu)^{3}}}
\end{gathered}
$$

where $f$, and $\zeta$ are frequency ratio and damping ratio of the TMD, defined as:

$$
f=\frac{\omega_{2}}{\omega_{1}} \quad \text { and } \quad \zeta=\frac{c}{2 \sqrt{k_{2} m_{2}}}
$$

where, $\omega_{2}, k_{2}, m_{2}$ and $c$, are the natural frequency, stiffness, mass and the damping of the TMD respectively and $\omega_{1}$ is the natural frequency of the main structure. In the structures with damping, however, the optimal TMD parameters should be obtained by using numerical methods(Rana and Soong, 1998)

TMDs have been applied in tall buildings to mitigate the vibration induced by wind and moderate earthquakes (Rana and Soong, 1998). Gutierrez Soto and Adeli (2013) present several real cases of application of TMDs in existing high rise buildings and towers around the world. 
Application and effectiveness of the TMDs in suppressing wind induced vibration in long span bridges have been investigated and approved (Lin et al. (2000), Gu et al. (1998), Honda et al. (1993), Domaneschi et al. (2015))

Hoang et al. (2008) investigated the seismic application of the TMDs and suggested the optimal design parameters of the TMDs. Kwon et al. (1998) investigated the application of TMDs in vibration control of bridges under the moving loads that lead to decrease in the vibration and quick dy out of the free vibration. Performance of the TMDs in vibration reduction of the railway bridges under the excitation of the high-speed trains have also been studied (Yau and Yang (2004b), Wang et al. (2003))

One of the main limiting characteristics of the STMDs is the narrow performance frequency range. One way to increase the performance range, is to use multiple tuned mass dampers(MTMDs). Multiple tuned mass dampers can be designed in either parallel or series configurations.(Kareem and Kline, 1995) Previous studies have shown that multiple tuned mass dampers (MTMDs) are more effective and more robust than single tuned mass dampers (STMDs) (Yamaguchi and Harnpornchai (1993), Igusa and Xu (1994))

Previous studies have shown the effectiveness of the MTMDs in suppressing the railway bridge vibrations induced by high speed trains. Lin and Chen (2005) studied the effect of the MTMDs using a simplified simply supported 2D beam as a bridge model excited by a passing high-speed train. They concluded that a $2 \%$ MTMD mass ratio, can reduce the maximum vertical acceleration by $57 \%$. Li et al. (2005) also investigated a simply supported girder model under the passing high-speed train and examined the response of the model in presence of MTMDs. They concluded that the maximum vertical dynamic deflection can be reduced by up to $61 \%$ for a $30 \mathrm{~m}$ long girder.

In the previous studies, the study bridges, are highly simplified and mostly modeled as a single 2D simply supported beams. This could lead to some limitations in applying their results to design a MTMD system for real cases. Therefor, the main aim of this study is to develop a more realistic 3D finite element (FE) model of an existing bridge and whereby, investigate the applicability of the MTMD systems. Furthermore, by examining different parameters of the MTMDs, a design procedure for real case application of MTMDs will be presented.

In this study, the available data of Banafjäl Bridge that is a high-speed composite railway bridge was utilized. 


\section{B.3 Modeling and analysis}

\section{B.3.1 The Banafjäl Bridge}

The Banafjäl Bridge, located on the Botniabanan, is a $42 \mathrm{~m}$ long simply supported high-speed railway bridge (figure B.2).

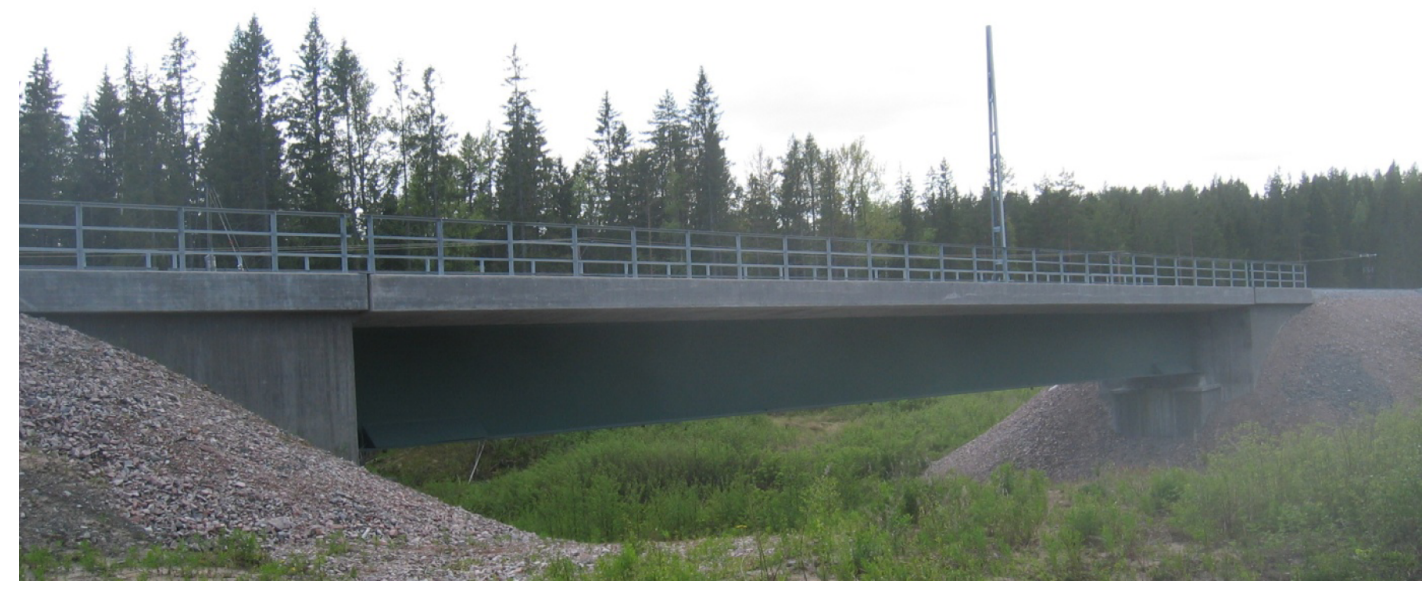

Figure B.2: The Banafjäl Bridge(Gillet, 2010)

The bridge's deck is consisted of a concrete slab that is carried by two steel girders i.e. I beams. The bridge has a horizontal curvature with the radius of $4000 \mathrm{~m}$. The concrete slab is $7.7 \mathrm{~m}$ wide and its thickness is varying from $250 \mathrm{~mm}$ to $400 \mathrm{~mm}$.

Each girder is made of three I beams in the longitudinal direction i.e. two side-beams and one mid-beam. The two side-beams have an identical cross section but different from the mid-beam. The girder's height is $2.5 \mathrm{~m}$. The two girders are connected to each other by means of cross beams in seven position along the bridge.

\section{B.3.2 Numerical evaluation of the TMDs}

A linear elastic 3D FE model of the Banafjäl Bridge was developed using the commercial FEM software, ABAQUS. For simplification, the horizontal curvature and the transverse slope of the rail-ballast system of the bridge was neglected. The concrete slab and the ballast were modeled as solid elements; the rails, the sleepers and the connector beams were modeled as beam elements; and the steel girders were modeled using shell elements. the damping ratio was assumed as $\zeta=0.5 \%$ (EN-1991-2, 2003). The model then calibrated against the measured frequencies of the first and second bending modes and the first torsional modes of the bridge.

The dynamic analysis was performed using modal superposition method under the defined dynamic load of passing HSLM-A train for speeds from 150 to $400 \mathrm{~km} / \mathrm{h}$. In the analysis based on the performed convergence analysis, the modes with the frequency of up to $40 \mathrm{~Hz}$ and the time step of $\Delta t=0.001 \mathrm{~s}$ were used. 


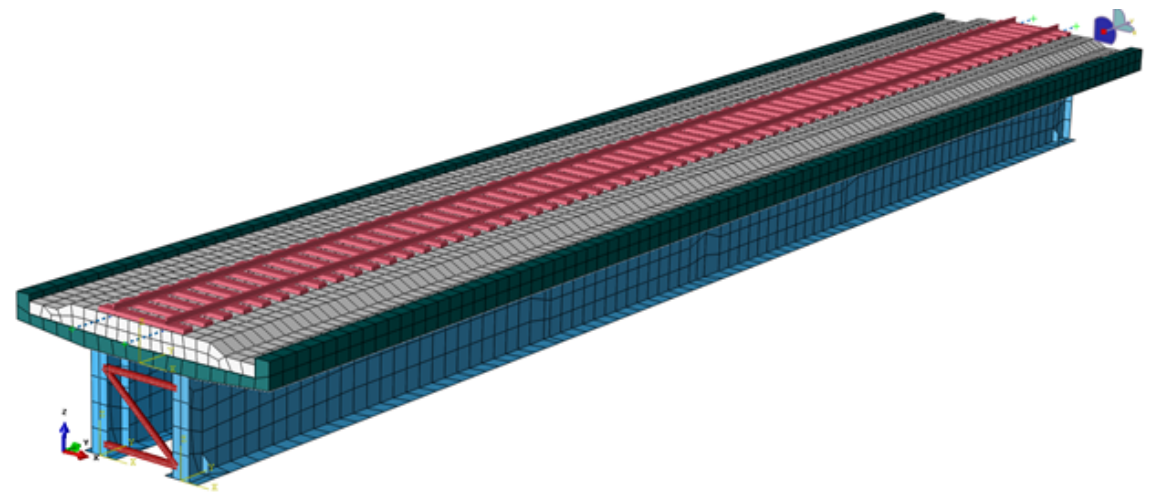

Figure B.3: Final FE model of the Banafjäl Bridge

The High Speed Load Models ,HSLM-A, were used to as the dynamic load (EN1991-2, 2003). The passing trains were modeled as moving point loads (see figure B.4), neglecting the damping and elastic behavior of the vehicle suspension system.

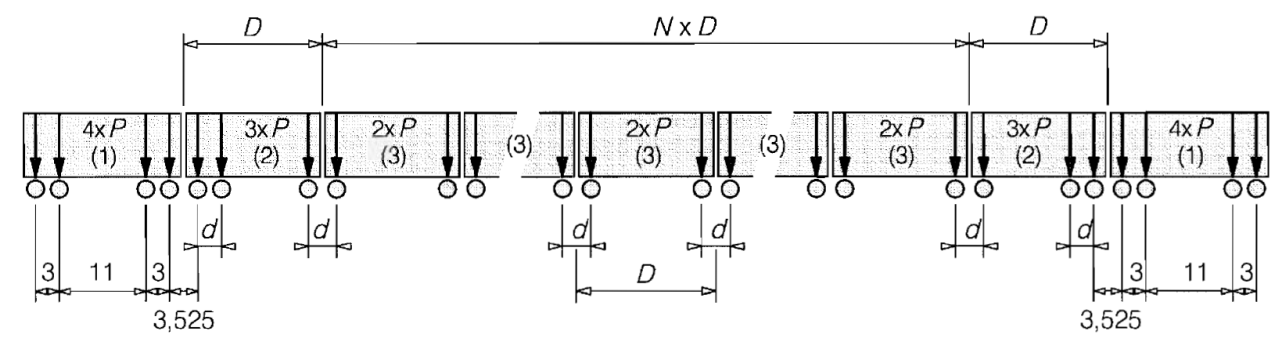

Figure B.4: High Speed Load Model, HSLM-A, (EN-1991-2, 2003)

Then the dynamic response of the bridge under the effect of the passing HSLMA trains were evaluated by determining the maximum vertical displacement and vertical acceleration close to the mid-span of the bridge at the resonance speed of the trains. The resonance speed of the trains can be calculated as( $\mathrm{Li}$ and $\mathrm{Su}, 1999)$ :

$$
v=\frac{\omega}{2 \pi J} L_{v} \quad(J=1,2,3, \ldots)
$$

where $L_{v}$ is the vehicle (in this case the coach) length $(D)$ and $\omega$ is the fundamental frequency of the bridge. Finally the train with the highest response was selected to be utilized for the rest of the study, which in this case was the HSLM-A3 train (Figure 2.5). Thus, from the equation (2.1) the resonance speeds for the HSLM-A3 train $(N=16, D=20 m, d=2 m$ and $P=180 k N)$ are going to be :

$$
v=\left[\begin{array}{llllll}
231.6 & 115.6 & 77.2 & 57.9 & \ldots &
\end{array}\right](\mathrm{km} / \mathrm{h})
$$

which $231.6(\mathrm{~km} / \mathrm{h})$ will produce the higher response.

The response of the bridge at the resonance speed of $231(\mathrm{~km} / \mathrm{h})$ is shown in figure 3.2 . 

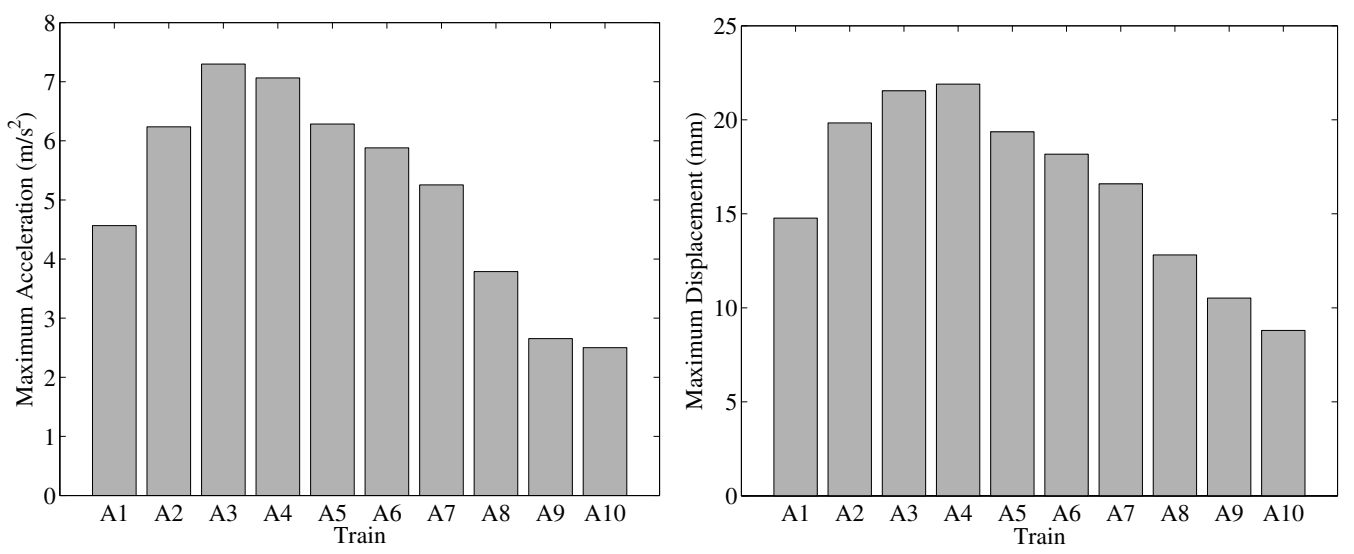

Figure B.5: Maximum vertical acceleration (right) and maximum vertical displacement at the mid-span of the Banafjäl bridge due to passing HSLM-A trains

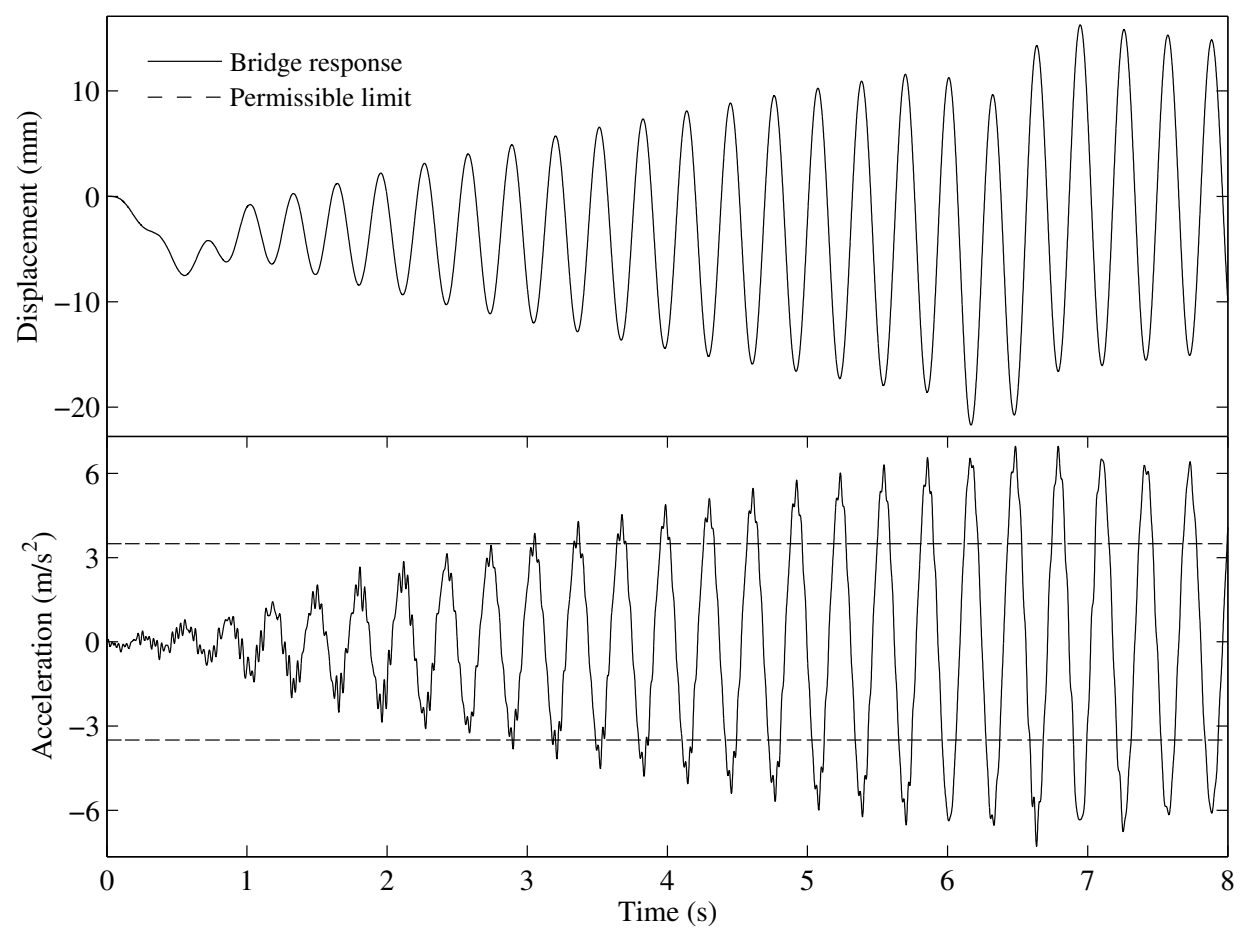

Figure B.6: The response of the Banafjäl bridge FE model to the passing HSLM-A3 train at the resonance speed of $231(\mathrm{~km} / \mathrm{h})$

As indicated in figure B.6, the maximum vertical acceleration (bottom plot) at the rails, exceeds the maximum permissible value (i.e. $3.5 \mathrm{~m} / \mathrm{s}^{2}$ ) showed by a dashed line. But the maximum vertical deflection (right) fulfill the necessary conditions and it is below the permissible limit that is: $L / 600=70 \mathrm{~mm}(\mathrm{EN}-1990,2002)$.

Thus, according to these results, the Banafjäl bridge does not fulfill the safety and comfort requirement conditions for a high speed train. Therefore it is necessary to improve the dynamic characteristics of the bridge using suitable actions. Applica- 
tion of TMDs could be one option to improve the dynamic response of the bridge, especially in the resonance condition.

\section{B.3.3 Application of TMDs}

The most dominant mode of the FE model was extracted that was the first vertical bending mode with the frequency of $f_{1}=3.2 \mathrm{~Hz}$ (see figure 2.7 ), by which the TMD parameters could be determined.
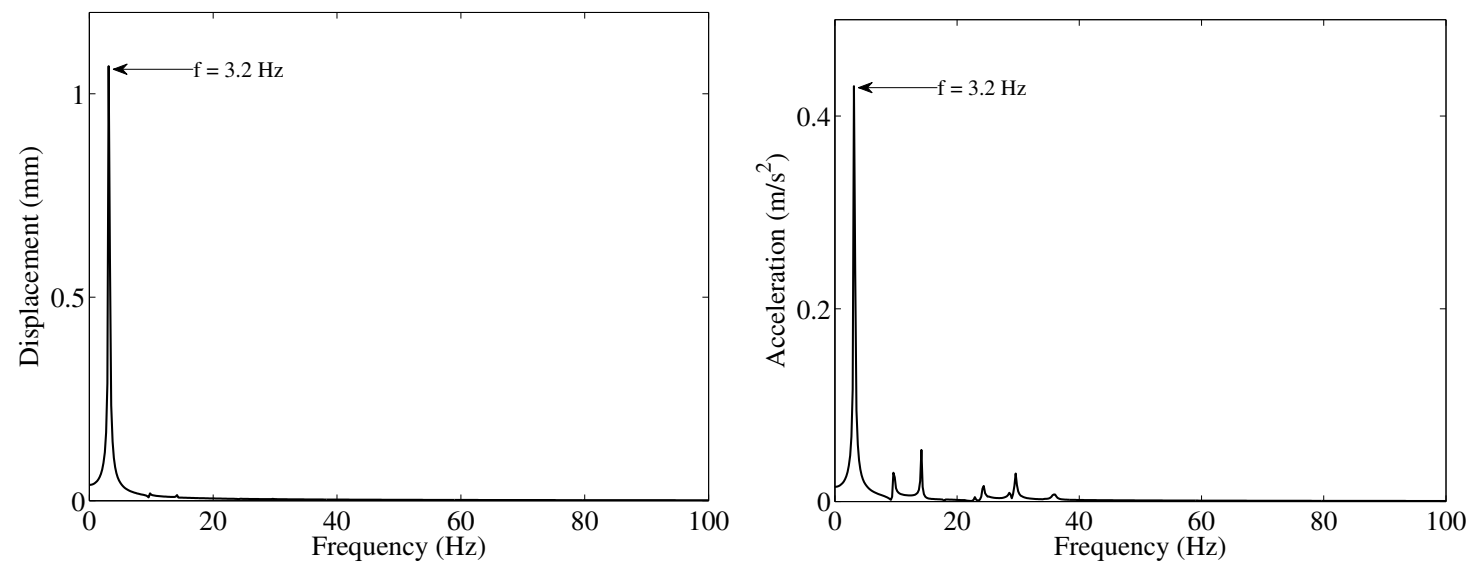

Figure B.7: Fundumental frequency of the Banafjäl Bridge FE model

Although the response frequency of the bridge will change under the load of the train(Li et al., 2003), in this study the fundamental frequency of the bridge without the train was utilized to estimate the TMD parameters to make the TMDs independent from the passing train.

In order to determine the suitable mass ratio of the MTMD systems, first a STMD was attached to the mid-span of the FE model that is the anti-node of the first vertical bending mode where the amplitude is maximal and the STMD is the most effective(Rana and Soong, 1998).

The method suggested by Den Hartog (1956), equations (B.1, B.2 and B.3) was used to estimate the optimal parameters of the STMDs.

According to the Eurocode (EN-1990, 2002) the maximum vertical acceleration of the deck in the ballasted tracks shall not exceed $3.5 \mathrm{~m} / \mathrm{s}^{2}$, therefore only mass ratios that fulfill this condition were considered. Three different mass ratios that had an acceptable effect on the response of the bridge were selected for further investigations. Although in most of the previous studies (Hoang et al. (2008), Luu et al. (2012), Yang et al. (2015), Lin and Chen (2005), Wang et al. (2003), Lin et al. (1994) and Yau and Yang (2004a)) the mass ratios of equal or higher than 1\% were selected, in this study based on the performance, all three selected mass ratios were below $1 \%$. The selected mass ratios were $\mu=0.22,0.44$ and 0.74 which correspond to the mass of $m=1.5,3$ and 5 tonnes (see figure B.8). 

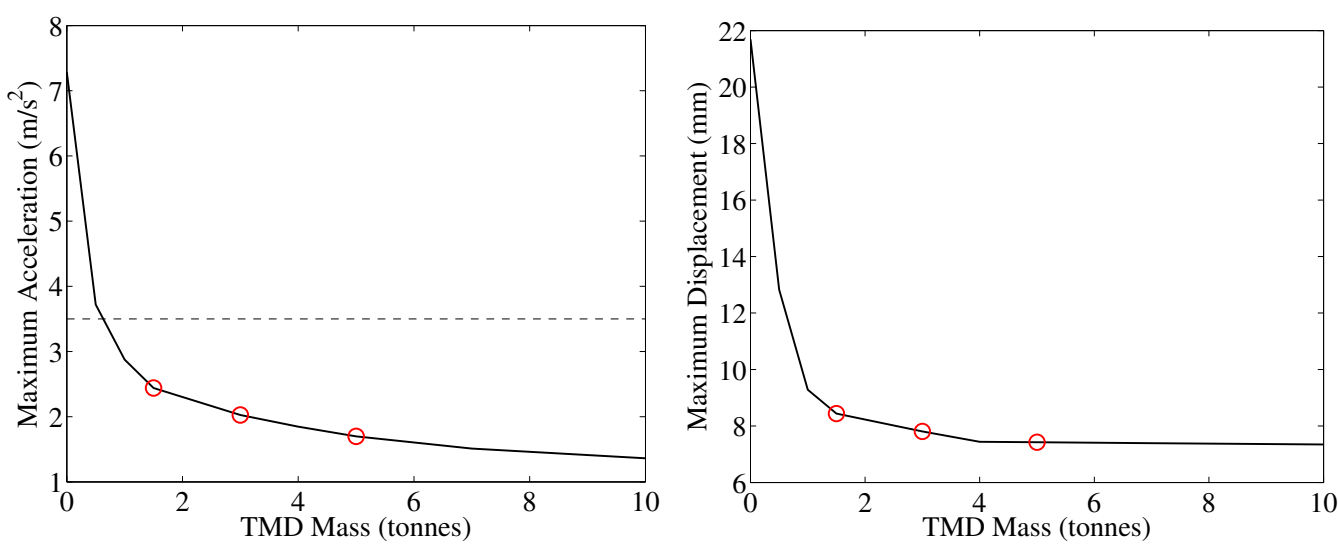

Figure B.8: Effect of the mass ratio on the performance of the STMD in decreasing maximum acceleration (left) and maximum displacement (right) at the mid-span of the bridge

Figure 3.3 presents the effect of a STMD on the response of the Banafjäl bridge FE model for different mass ratios of the STMD.
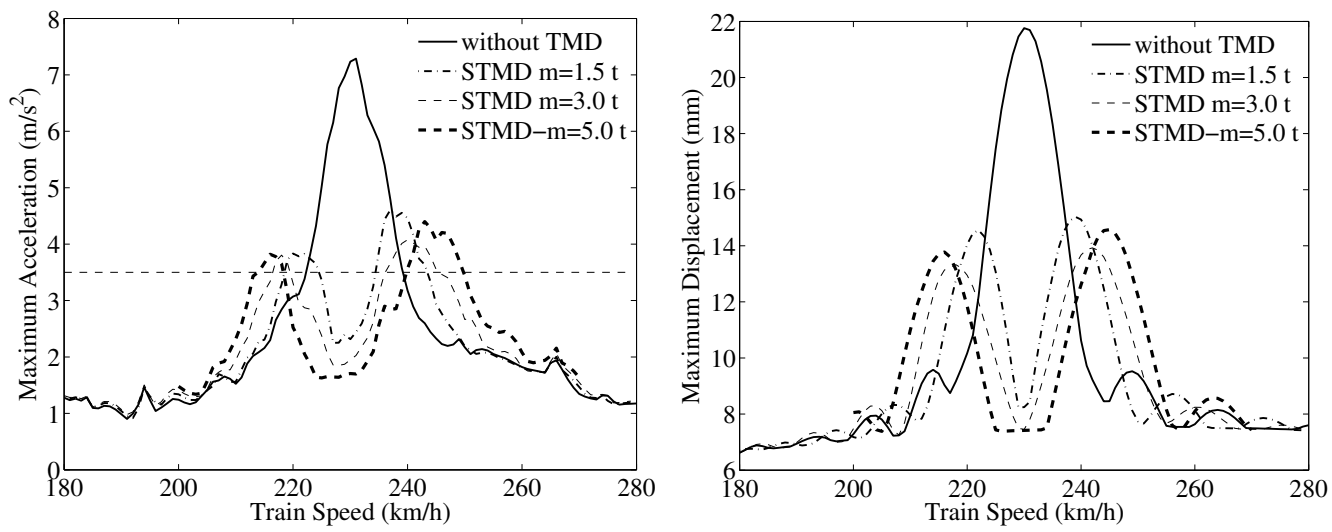

Figure B.9: Effect of a STMD on the dynamic response of the Banafjäl bridge FE model with the mass ratios of $0.22 \%, 0.44 \%$ and $0.74 \%$, which correspond to the mass of $1.5,3.0$ and 5.0 tonnes respectively.

In the figure B.9, the solid line response of the model without TMDs, which indicates that in the speed range of $220 \mathrm{~km} / \mathrm{h}$ to $240 \mathrm{~km} / \mathrm{h}$, the vertical acceleration exceeds the acceptable limit and reach the maximum of $7.5 \mathrm{~m} / \mathrm{s}^{2}$ at the speed of $231 \mathrm{~km} / \mathrm{h}$.

As indicated in figure B.9, the STMD alters the dynamic response of the bridge from one peak resonance to two distinctive peak resonances. Whereby, the resonance peak amplitude decrease significantly. But the effect of the STMD disappear when the train speed deviate from resonance speed of $231 \mathrm{~km} / \mathrm{h}$ which STMD is tuned to.

All of the three mass ratios decrease the resonance peak of the maximum vertical displacement and acceleration at the resonance speed of $231 \mathrm{~km} / \mathrm{h}$ below the acceptable limit. But the two new response peaks of the vertical acceleration, in the new bridge-STMD system are still unacceptable. The maximum vertical acceleration at 
the resonance speed of $231 \mathrm{~km} / \mathrm{h}$, has been reduced by $-67 \%,-72 \%$ and $-77 \%$ for the 1.5, 3 and 5 tonnes of STMD respectively. While the maximum vertical acceleration in the model with STMD, including the two new distinct peeks, is smaller than the model without STMD by only $-37 \%,-44 \%$ and $-40 \%$ for the $1.5,3$ and 5 tonnes of STMD respectively.

Thus, although even a small STMD can effectively decrease the the resonance peak, but the two new generated peaks still overshoot the limiting threshold even with a heavier STMDs.

In spite of that the higher mass ratios increase the effective range of the STMD, but still a STMD can not be a sufficient solution for vibration control of the Banafjäl bridge.

One solution to increase the effective range of the TMD, is that instead of using one large STMD that tuned to the resonance frequency, the total mass can be divided between several smaller TMDs that tuned to the resonance frequency with a small deviation. In other words, instead of one large concentrated mass, the total mass can be spread over a range of frequencies to produce a curve with several smaller peak instead of two large peaks.

Different configuration of the multiple tuned mass dampers (MTMDs) with the same total ratio as STMDs, were investigated. The number of TMDs in the MTMD configuration were selected as odd numbers $(N=1,3,5)$ that the middle one attached to the mid-span of the bridge and the other TMDs were attached with some deviation from the mid-span. Figure (2.9) shows the 5 TMDs attached to the bridge in a parallel configuration.

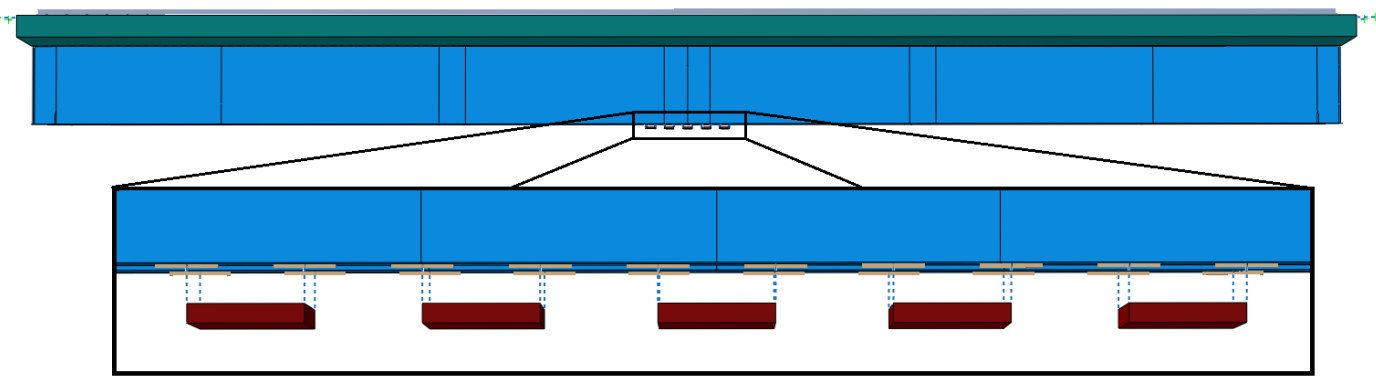

Figure B.10: MTMDs attached to the mid-span of the bridge model

The frequency of the TMDs in the MTMDs systems were uniformly distributed around their average natural frequency by $\Delta \omega$. The frequency of the $i^{\text {th }}$ TMD can be determined as(Li, Su, and Fan, 2005):

$$
\omega_{i}=\omega_{T}\left[1+\left(i-\frac{N+1}{2}\right) \frac{\Delta \omega}{N-1}\right] \quad(i=1,2,3, \ldots, N)
$$

where $\omega_{T}$ is the average frequency of the MTMDs that is in fact the optimal frequency of a STMD with the same mass ratio as the overall mass ratio of the MTMDs, 
$\mathrm{N}$ is the number of TMDs and $\Delta \omega$ is the frequency range of the MTMDs that can be determined as:

$$
\Delta \omega=\frac{\omega_{N}-\omega_{1}}{\omega_{T}}
$$

The values of frequency range were selected as $(\Delta \omega=5,10,15,20(\%))$. Parameters of the TMDs used in this study for $\Delta \omega=10(\%)$ are presented in table (2.6):

Table B.1: Parameters of the STMD and MTMDs used in this study for $\Delta \omega=10(\%)$.

\begin{tabular}{|c|c|c|c|}
\hline $\begin{array}{l}\text { Number of } \\
\text { TMDs }\end{array}$ & $\begin{array}{c}\text { Total } \\
\text { weight } \\
m \text { (tonnes) }\end{array}$ & $\begin{array}{c}\text { Total } \\
\text { mass ratio } \\
\mu(\%)\end{array}$ & $\begin{array}{c}\text { Frequency ratios } \\
\text { of the TMDs } \\
\Delta \omega=10 \%\end{array}$ \\
\hline 1 & 1.5 & 0.22 & 0.998 \\
\hline 1 & 3.0 & 0.44 & 0.996 \\
\hline 1 & 5.0 & 0.74 & 0.993 \\
\hline 3 & 1.5 & 0.22 & 0.9490 .9991 .049 \\
\hline 3 & 3.0 & 0.44 & 0.9490 .9991 .048 \\
\hline 3 & 5.0 & 0.74 & 0.9480 .9981 .047 \\
\hline 5 & 1.5 & 0.22 & $\begin{array}{llll}0.950 & 0.975 & 0.999 & 1.0251 .050\end{array}$ \\
\hline 5 & 3.0 & 0.44 & 0.9490 .9740 .9991 .0241 .049 \\
\hline 5 & 5.0 & 0.74 & 0.9490 .9740 .9991 .0241 .048 \\
\hline
\end{tabular}

In total, 33 different scenarios of the application of TMDs on the Banafjäl FE model were investigated. Then the scenario with the best performance and sufficient mass ratio was selected as the damping solution for the bridge.

Figure (3.4) shows the effectiveness of the MTMDs consist of five TMDs with the total mass ratios of $0.22 \%, 0.44 \%$ and $0.74 \%(\mathrm{~m}=1.5,3,5)$ and the total frequency range of $5 \%, 10 \%, 15 \%$ and $20 \%$.

The top row of the figure(B.11), indicate a set of scenarios with five TMDs. As it can be seen, there is a frequency range in which the MTMDs have the best performance relative to other frequency ranges. In the optimal frequency range the response curve of the vertical displacement is relatively flat, whereas the other frequency ranges have one or two distinctive larger peaks. This optimal frequency range is $8.8 \%$ for the mass ratio of $0.22 \%$. Furthermore, the maximum acceleration curve of the optimal frequency range produce the lowest acceleration that is below the maximum acceptable limit, while other frequency ranges often overshoot the threshold. This behavior is presented in figure (B.12).

Thus if the fundamental frequency of the bridge could be determined accurately, and the production procedure would carried out perfectly, this option could control the bridge's vibration effectively and with a lower cost. The maximum vertical acceleration decreased by $-54 \%$ and maximum vertical displacement by $-50 \%$.

Regardless of the sensitivity of this option, the limiting factor for this option is the high amplitude of the vibration of the MTMDs themselves, which needs a larger 

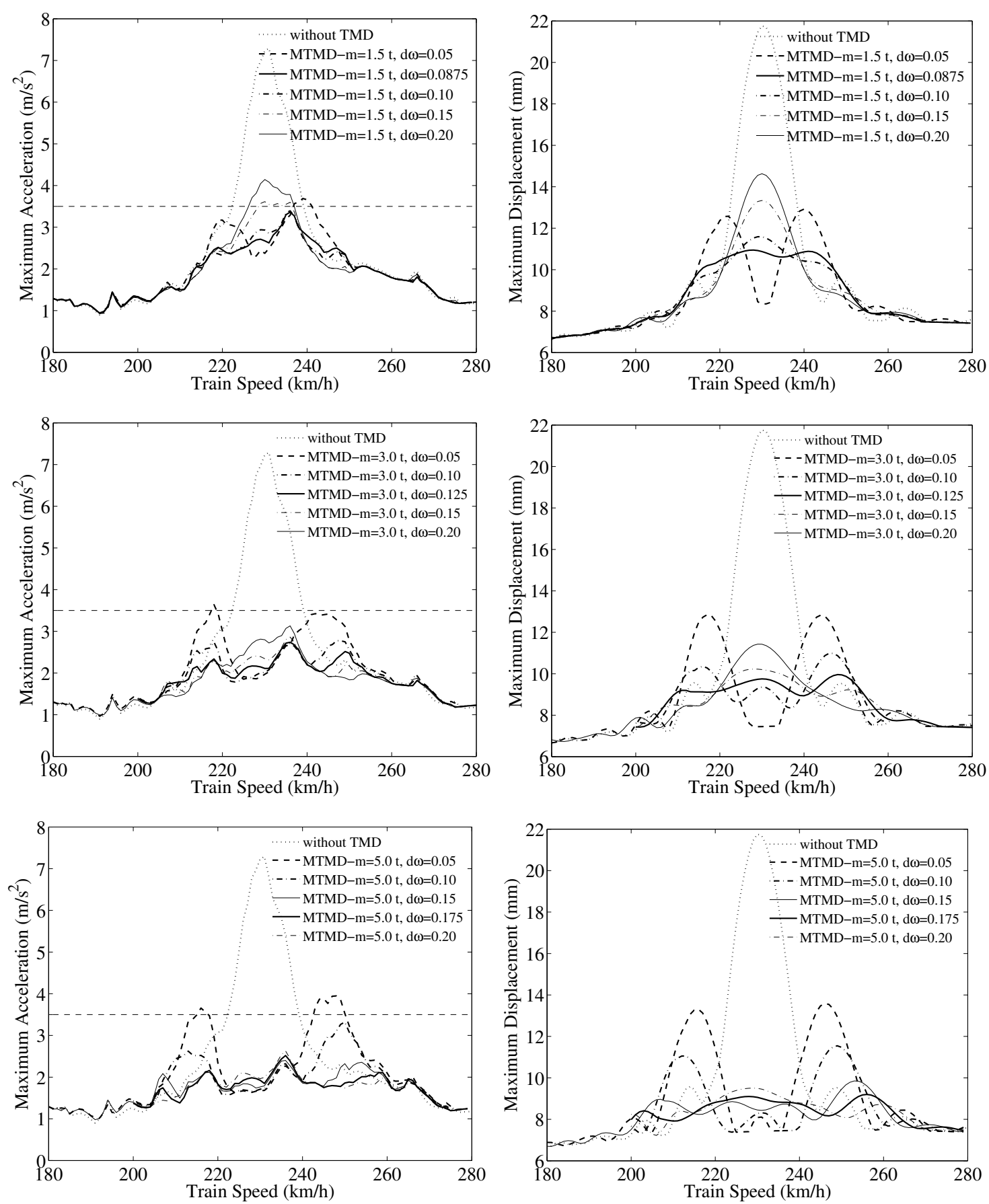

Figure B.11: Effect of a MTMD consist of 5 TMDs on the dynamic response of the Banafjäl bridge FE model with the mass ratios of $0.22 \%$ (the top row), $0.44 \%$ (the middle row) and $0.74 \%$ (the bottom row), which correspond to the mass of $1.5,3.0$ and 5.0 tonnes and with the total frequency deviation of $5 \%, 10 \%, 15 \%$ and $20 \%$.

room for the oscillations. This may also cause fatigue in the MTMD spring and damping elements during the operation period.

The middle row of the figureB.11 corresponds to the mass ratio of $0.44 \%$ with five 
TMDs, which indicate, by increasing the mass ration from $0.22 \%$ to $0.44 \%$ The MTMD system become even more efficient. The best performing scenario has the higher frequency range of $12.5 \%$. The maximum vertical acceleration and displacement have decreased by $-63 \%$ and $-54 \%$ respectively. Therefore while this option could be less economical relative to the previous option, but it has a better performance.

The lower row of the figureB.11 shows the set of scenarios with three 3 TMDs and the mass ratio of $0.74 \%$. The optimal frequency range in these scenarios is $17.5 \%$. Which has the best performance among all tested scenarios with $66 \%$ and $58 \%$. decrease in the maximum vertical acceleration and displacement respectively.
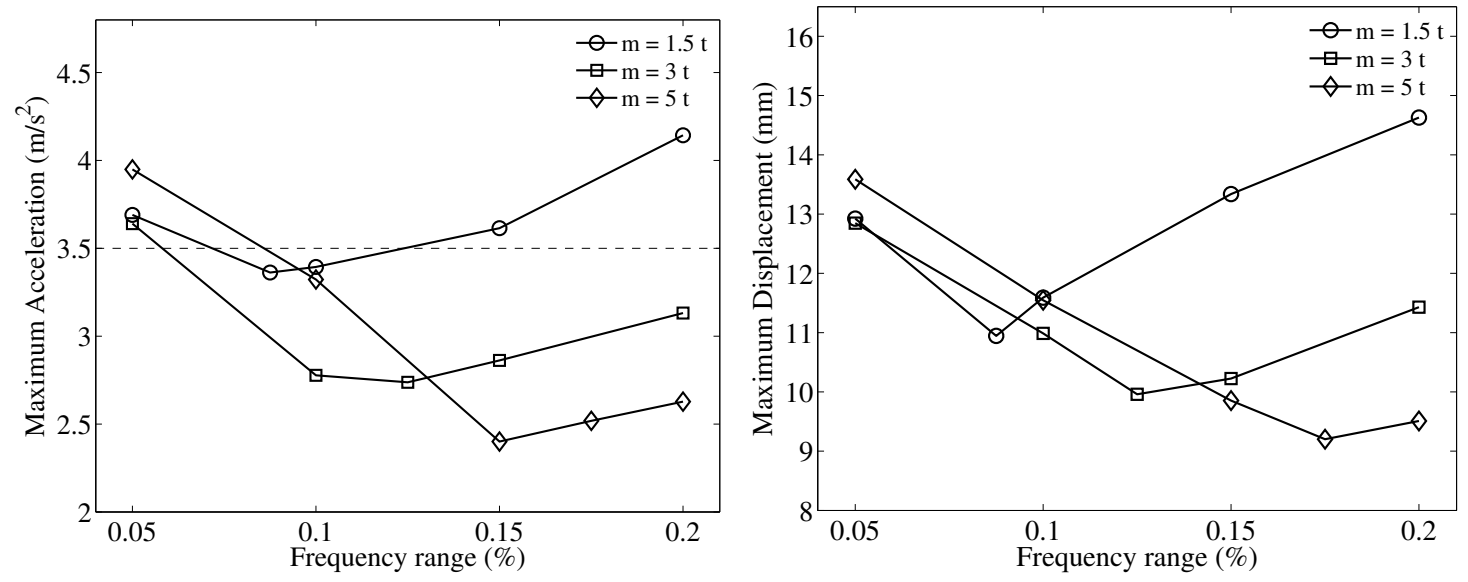

Figure B.12: Relation between the frequency range of thr MTMDs and the maximum response in the Banafjäl bridge FE model

In the scenario with three TMDs and $0.74 \%$ mass ratio, despite that the maximum acceleration reduced effectively, but the maximum displacement curve has four distinctive relatively large peaks which is far from the optimum performance (see figure 3.4). This indicate that three numbers of TMDs are not sufficient enough for this mass ratio, therefore, it can be seen that the higher mass ratio requires the higher numbers of TMDs to have an optimal performance.

Figure B.13 shows the relation between the mass ratio and the optimum frequency range of the MTMDs.

According to the figure 3.8, there is perfect linear relation between mass ratio and the optimum frequency range. Therefore the optimum frequency range for other mass ratios can be interpolated. Extrapolation for higher mass ratios however, is not recommended, since it may need higher numbers of TMDs in order to produce the optimum results.

A summery of the performance of the optimal scenarios (i.e. their ability to decrease the maximum acceleration and displacement in the mid-span of the Banafjäl bridge FE model) is presented in the table B.2.

According to the results of the current study, all of the selected mass ratios of the 


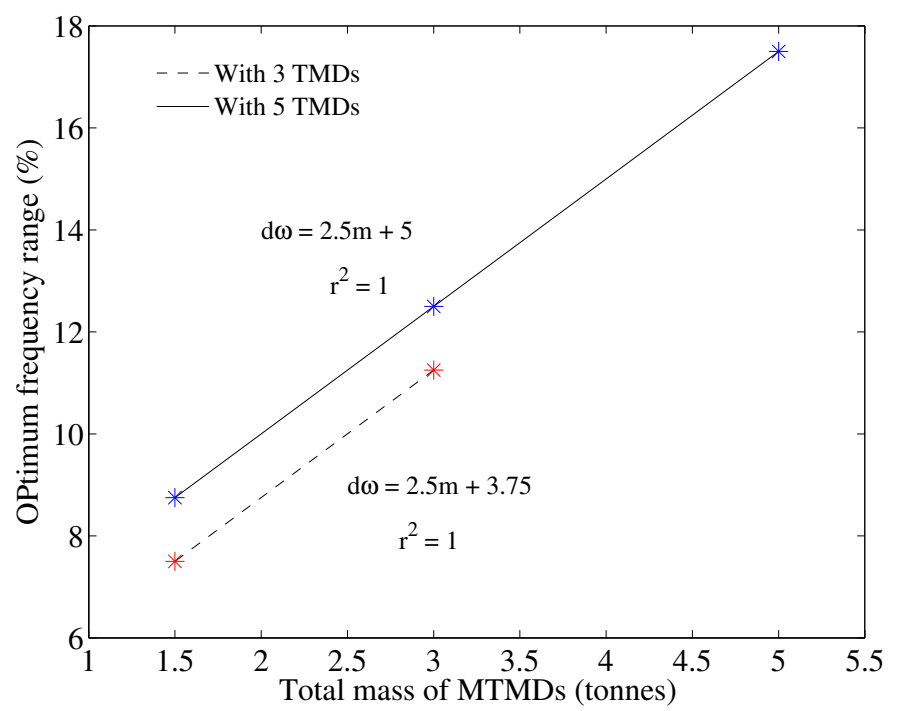

Figure B.13: The relation between mass ratio and the optimum frequency range

Table B.2: Summery of the best performing scenarios of using MTMDs on the Banafjäl bridge FE model.

\begin{tabular}{lcccc}
\hline & Number of & \multicolumn{3}{c}{ Mass ratio } \\
\cline { 3 - 5 } Variable & TMDs & $0.22 \%$ & $0.44 \%$ & $0.74 \%$ \\
\hline Acceleration $\left(m / s^{2}\right)$ & Without TMDs & 7.29 & 7.29 & 7.29 \\
& 1 TMDs & $4.59(-37 \%)$ & $4.01(-44 \%)$ & $4.40(-40 \%)$ \\
& 3 TMDs & $3.37(-54 \%)$ & $2.78(-62 \%)$ & $3.03(-58 \%)$ \\
& 5 TMDs & $3.36(-54 \%)$ & $2.74(-63 \%)$ & $2.52(-66 \%)$ \\
Displacement $(m m)$ & & & \\
& & & 21.8 & 21.8 \\
& Without TMDs & 21.8 & $21.8 \%$ \\
& 1 TMDs & $15.0(-32 \%)$ & $14.0(-36 \%)$ & $14.5(-34 \%)$ \\
& 3 TMDs & $11.1(-49 \%)$ & $10.2(-53 \%)$ & $11.9(-46 \%)$ \\
& 5 TMDs & $10.9(-50 \%)$ & $10.0(-54 \%)$ & $9.2(-58 \%)$ \\
\hline
\end{tabular}

MTMD systems effectively decrease the mid-span vibration of the Banafjäl bridge in the warm season (i.e. $E_{\text {ballast }}=200 M P a$ ) and control the maximum acceleration below the acceptable limit of $3.5 \mathrm{~m} / \mathrm{s}^{2}$. However, the MTMD systems with 5 TMDs are preferred since, they are easier to handle due to the lighter weight and furthermore, they could be more tolerant against the possible failure of one of the TMDs.

\section{B.3.4 Sensitivity analysis}

One of the main issues of the application of the TMDs is detuning. Detuning can lead to a significant loss in the performance of the TMDs. Structural deterioration of the main structure, inadvertent change in the structure's dynamic characteristics, inaccurate determination of the dynamic characteristics of the main structure etc. 
can result in detuning of the TMDs(Roffel et al., 2011). Seasonal change in the dynamic properties of the of the railway bridges may happen due to freezing and ice forming that occurs in the the ballast. According to Gonzales et al. (2013) the ballast stiffness can increase from $200 \mathrm{MPa}$ in the warm season to $1400 \mathrm{MPa}$ in the cold season.

Thus two scenarios were defined to investigate the detuning effect on the selected best case scenario. In the the first scenario The effect of the under-estimation of the fundamental frequency of the bridge was investigated.

Figure 3.9 indicates the maximum tolerance of the investigated MTMD systems with 5 TMDs to the under-estimation of the dominant frequency without overshooting the maximum limt.

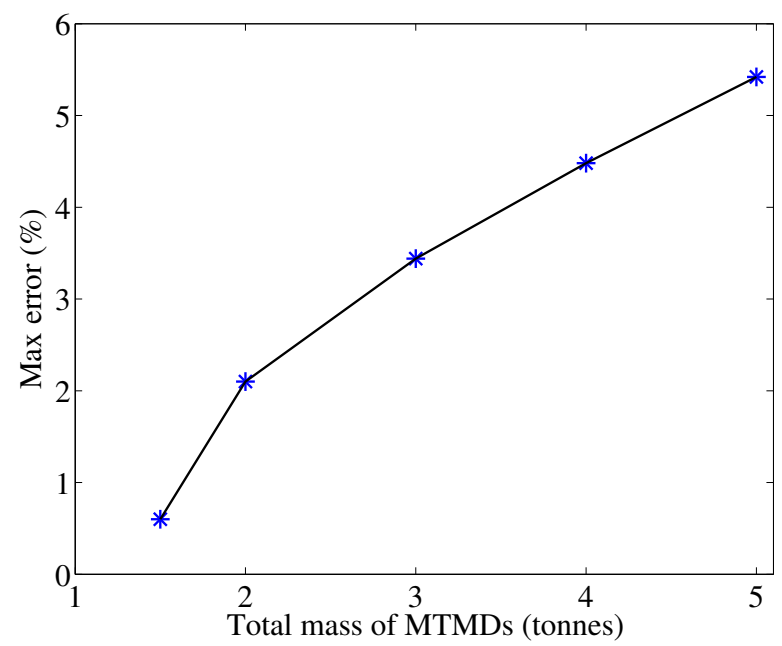

Figure B.14: maximum tolerance of the MTMD systems with five TMDs for different mass ratios.

As shown in figure B.14, the tolerance of the MTMD system will non-linearly increase with increase in the mass ratio which confirm the results of the previous studies (Rana and Soong, 1998). Figure 3.9 can be useful to determine the best suitable mass ratio based on the maximum acceptable error in the determination of the fundamental frequency of the bridge.

In the second scenario the effect of the change in ballast stiffness which in fact increase the natural frequency by $5 \%$ from $3.2 \mathrm{~Hz}$ to $3.4 \mathrm{~Hz}$ was studied. Therefor according to the figure B.14, the mass ratio should be at least $0.6 \%$ ( $m=4$ tonnes) for the MTMD system with 5-TMDs to perform effectively in both warm and cold season. Moreover, from figure B.13, the optimal $d \omega$ for the mass ratio of $\mu=$ $0.6 \%$ ( $m=4$ tonnes) is $d \omega=15 \%$. Figure (B.15) shows the effectiveness of the 5 MTMDs with the mass ratio of $\mu=0.6 \%$ ( $m=4$ tonnes) and $d \omega=15 \%$ at the resonance speed of the HSLMA-A3 train.

Figure B.16 indicate the the performance of the selected scenario $(\mu=0.6 \%, d \omega=$ $15 \%$ and $N=5$ ) that can perform in both warm and cold seasons.

As presented in figure B.16 A MTMD system with five TMDs and the mass of 4 


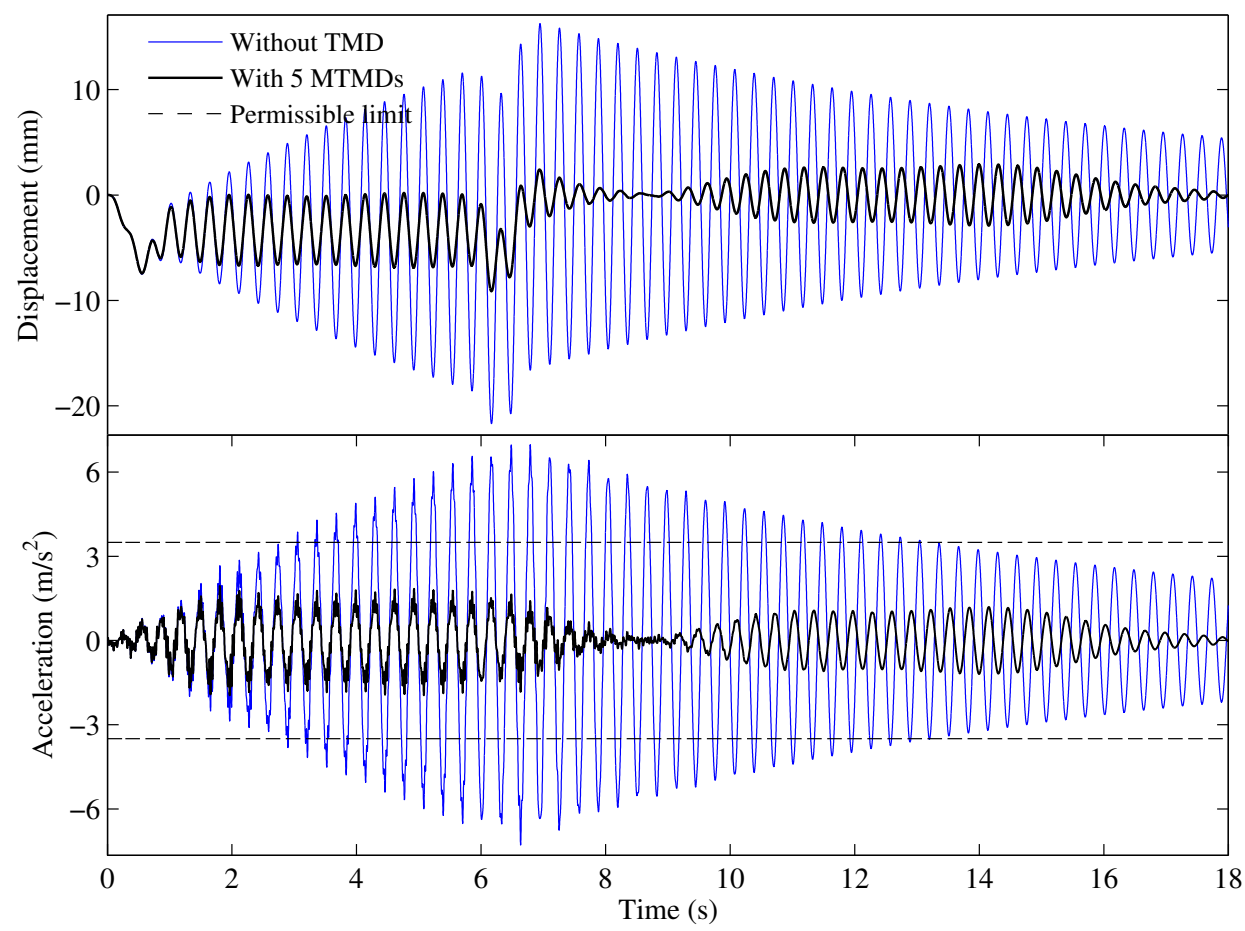

Figure B.15: Effectiveness of the 5 MTMDs with the mass ratio of $\mu=0.6 \%(m=4$ tonnes) and $d \omega=15 \%$ at the resonance speed of the HSLMA-A3 train.
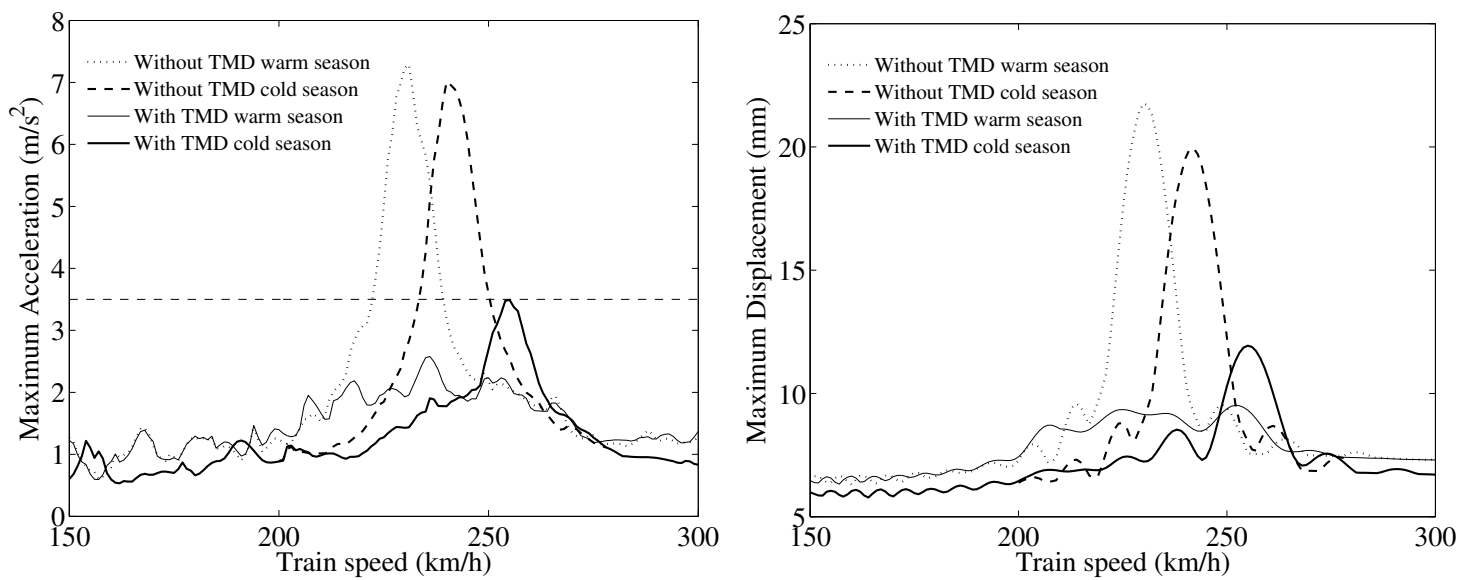

Figure B.16: Performance of the selected MTMD system $(\mu=0.6 \%, d \omega=15 \%$ and $N=5$ ) in both warm and cold year

tonnes can successfully control the vibration during the whole year. But there is no room for any further error or deviation from the tuned frequency. 


\section{B.4 Conclusions}

In this study The Banafjäl bridge located on the Botniabanan in northern Sweden was studied. A 3D FE model of the bridge was developed using a commercial FE software, Abaqus and calibrated against the measured data of the bridge. The dynamic response of the bridge's FE model was investigated under the dynamic load of the passing HSLM-A train using modal dynamic analysis. Based on the results of this study, a 4 tonnes MTMD system with 5 TMDs $(\mu=0.6 \%$ and $d \omega=15 \%)$ attached to the mid-span of the Banafjäl bridge, can effectively control the resonance vibration of the bridge that induced by the HSLMA-A3 train during both warm and cold seasons.

\section{B.5 Design procedure of MTMD systems}

Based on the performed study, the following step-by-step instructions could be helpful in designing an MTMD system for a high-speed railway bridge that is susceptible to resonance, using a calibrated FE model:

1. Determine the worst case scenario of the external dynamic load between suggested train models in their resonance speed (see figure B.5).

2. Determine the most dominant mode and its frequency in the working speed range of the bridge using for instance a pulse load (see figure B.7).

3. Attache a single TMD to the anti node of the dominant mode.

4. Tune the STMD to the dominant frequency using Den Hartog (1956) method (equations B.1 and B.2)

5. Evaluate the bridge-STMD system for different mass ratios under the passing selected train model at its resonance speed (see figure B.8).

6. select three mass ratios that effectively control the resonant vibration of the bridge for further investigations using MTMDs (see figure B.8).

7. Choose a suitable numbers of the TMDs in the MTMD system, as higher numbers of TMDs have a better performance but more costly.

8. Determine the optimal frequency range $(d \omega)$ by running the model for different frequency ranges (see figures B.11 and B.12) and draw a relation between mass ratio and optimal $d \omega$ (see figure B.13).

9. Evaluate the optimal MTMDs for their maximum tolerance against errors in the design parameters or detuning (e.g. underestimation of the dominant frequency), and draw a relation between the mass ratio and the maximum error that each MTMD system can tolerate (see figure B.14). 
10. Choose a maximum acceptable error in the design or maximum acceptable detuning, then, determine the suitable mass ratio and optimal $d \omega$ using relations generated at the steps 9 and 8 respectively.

\section{B.6 Future studies}

As mentioned in the section 1.5, current work has some limitations due to assumptions have made in order to simplify the problem. Thus any more profound studies that could eliminate any or some of the mentioned limitations could be a suggestion for further studies:

- Investigate the effect of horizontal curvature of the bridge and the transverse slope of the ballast and whereby investigate the effects of torsional modes.

- Investigate the effect of possible non-linearity in the dynamic response of the bridge.

- Investigate the effect of foundation an bearings on the dynamic response of the bridge.

- Investigate the effect of suspension system of the vehicle on the total responce of the bridge. 
TRITA -BKN. Master Thesis 471, 2015

ISSN 1103-4297

ISRN KTH/BKN/EX-471-SE 